\title{
Generations of Advantage.
}

\section{Multigenerational Correlations in Family Wealth}

\author{
Fabian T. Pfeffer ${ }^{1}$ \\ University of Michigan \\ $\&$ \\ Alexandra Killewald \\ Harvard University
}

October 2017

\section{Forthcoming in Social Forces}

\author{
Keywords: \\ Social Mobility, Wealth, Multigenerational, Family, Life Course
}

\footnotetext{
${ }^{1}$ This work has been supported by an award from the Russell Sage Foundation and the W.K. Kellogg Foundation. The collection of data used in this study was partly supported by the National Institutes of Health under grant number R01 HD069609 and the National Science Foundation under award number 1157698. Any opinions expressed are those of the authors alone and should not be construed as representing the opinions of the funding agencies. Earlier versions of this paper were presented at the Annual Meeting of the American Sociological Association, the Annual Meeting of the Society for the Advancement of Socio-Economics, and a Federal Reserve System Community Development Research Conference (proceedings published by the Federal Reserve Bank of St. Louis). We thank Pablo Mitnik, Matthew Salganik, Trina Shanks, and the anonymous reviewers for helpful comments on an earlier version, as well as Andreja Siliunas for excellent research assistance. A replication package containing the data and code used for this paper is available through the PSID Public Data Extract Repository at https://www.openicpsr.org/openicpsr/psid (\#101094). Please direct all correspondence to Fabian T. Pfeffer, University of Michigan, 4213 LSA Building, 500 South State Street, Ann Arbor, Michigan 48109, fpfeffer@umich.edu
} 


\begin{abstract}
Inequality in family wealth is high, yet we know little about how much and how wealth inequality is maintained across generations. We argue that a long-term perspective reflective of wealth's cumulative nature is crucial to understand the extent and channels of wealth reproduction across generations. Using data from the Panel Study of Income Dynamics that span nearly half a century, we show that a one decile increase in parents' wealth position is associated with an increase of about 4 percentiles in their offspring's wealth position in adulthood. We show that grandparental wealth is a unique predictor of grandchildren's wealth, above and beyond the role of parental wealth, suggesting that a focus on only parent-child dyads understates the importance of family wealth lineages. Second, considering five channels of wealth transmission — gifts and bequests, education, marriage, homeownership, and business ownership — we find that most of the advantages arising from family wealth begin much earlier in the life-course than the common focus on bequests implies, even when we consider the wealth of grandparents. We also document the stark disadvantage of African-American households in terms of not only their wealth attainment but also their intergenerational wealth mobility compared to whites.
\end{abstract}




\section{INTRODUCTION}

Inequality in U.S. family wealth is high (Pfeffer, Danziger, and Schoeni 2013; Piketty 2014; Wolff 2016), raising concerns about the degree to which the greatly unequal distribution of wealth between families is also bound to be maintained across generations. Social mobility the extent of (dis)similarity between parents and children in socioeconomic outcomes — is of long-standing interest to social scientists as an indicator of a society's openness (Becker and Tomes 1979; Blau and Duncan 1967). Although wealth is an important and distinct dimension of economic success (Spilerman 2000; Killewald, Pfeffer, and Schachner 2017), wealth has rarely been considered in this perspective, in part due to data limitations. Instead, the study of intergenerational persistence is still chiefly concentrated on income, earnings, and occupations (Torche 2015).

To study wealth mobility, it is tempting to simply apply the same assumptions and analytic techniques typically used to study intergenerational persistence in income, education, and occupations. This approach, however, is inappropriate because wealth is a different kind of resource, accumulated as the product of circumstances across the life course and potentially transferred directly to children from parents and even grandparents. Thus, we argue that a longterm perspective is needed to understand to what extent wealth positions are reproduced across generations and the channels through which this reproduction occurs. Failure to do so may not only underestimate the extent to which wealth is passed down across generations but potentially also impede our understanding of how wealth is maintained across generations.

In addition to direct transfers of wealth across generations through either bequests or intervivos transfers (gifts), family investments in children may have indirect effects on offspring wealth. Throughout, when we refer to (grand)parental investments or channels of transmission, 
we include either direct transfers from (grand)parents to children or other, indirect ways by which (grand)parental wealth is associated with the wealth of descendants, such as by supporting their educational attainment that in turn allows them to accumulate wealth.

We place wealth accumulation within the context of individuals' own life course and their relationships to other family members (Elder 1994). Within individuals' lives, we consider how the intergenerational similarity in wealth positions relates to other age-graded processes, such as education, marriage, and parental death. We acknowledge that these earlier life events in turn have downstream consequences for wealth in middle age. Drawing on the concept of linked lives, we recognize that wealth accumulation takes place in the context of family relationships across the life span. In particular, we augment the typical exclusive consideration of parent-child relationships to consider the contribution of grandparents.

Our analyses make two main contributions to the understanding of intergenerational wealth reproduction. First, we argue that prior studies of the intergenerational persistence of wealth have understated within-family wealth persistence because they have considered only the association between parents and children. While examining parent-child associations is meaningful, given that parents are likely to be the primary investors in their children's future, this approach imposes a narrow conception of family relations and intergenerational ties. Mare (2011) and Pfeffer (2014) hypothesized that multigenerational (that is, three or more generation) associations should be particularly strong for wealth compared to other markers of socio-economic attainment. We therefore expand our view beyond the parent-child relationship and consider the persistence of wealth across three generations: grandparents and their adult grandchildren. We show that grandparents' wealth is a unique predictor of grandchildren's wealth, above and beyond the role of parental wealth. 
Second, understanding the mechanisms responsible for the similarity in wealth positions across generations requires attention to (grand)parental investments made at different points in children's life course. Investments by parents and grandparents that shape descendants' early adulthood outcomes, particularly educational attainment, will pay dividends throughout children's lives, while later-life asset transfers, such as bequests, will have less time to appreciate and contribute to overall wealth. Here, too, the consideration of grandparental wealth is important, since grandparents' asset accumulation, unlike that of parents, reaches its peak during children's earlier life course and may thus be more readily available to support early-life investments. We document descriptively to what extent channels of wealth transmission concentrated in early-life (education), early- to mid-life (marriage, homeownership, and business ownership), and later-life (inheritance) can explain the similarity in wealth positions across generations. We find that the common focus on inheritance is misguided, since most of the advantages arising from family wealth already accrue from investment that begins much earlier in the life-course, especially education, even when we consider the wealth of grandparents.

\section{THEORETICAL BACKGROUND AND PRIOR WORK}

Typically, household wealth is defined as net worth, which is the gross value of both financial assets and real property less all debts (Keister and Moller 2000; Spilerman 2000). Compared to income, wealth in the United States is substantially more unequally distributed (Keister and Moller 2000). Wealth is in turn associated with a wide range of outcomes, including family formation and the educational success of offspring (for a review, see Killewald, Pfeffer, and Schachner 2017). Furthermore, these associations are not fully explained by standard measures of socioeconomic advantage, such as income, education, and occupation. The wealth 
distribution is thus an important and distinct measure of the concentration of social inequality and advantage.

While a large literature in economics and sociology has investigated intergenerational associations in income and earnings, occupations, and education (Blau and Duncan 1967; Solon 1992; Pfeffer 2008; Hertz et al. 2007; Erikson and Goldthorpe 1992), our knowledge of how similar the wealth of parents is to the wealth of their offspring relies on very few studies. These studies estimate an intergenerational wealth elasticity — based on the association in logged parent and child wealth — between 0.28 (Conley and Glauber 2008) and 0.37 (Charles and Hurst 2003). Mulligan's (1997) estimate of 0.33 increases to 0.53 when she applies an instrumental variable approach designed to correct for attenuation bias. In Sweden, the correlation between parent and child wealth ranks is also around 0.3-0.4 (Adermon, Lindahl, and Waldenström 2016), while the Danish rank correlation is a little lower at 0.24 (Boserup, Kopczuk, and Kreiner 2014).

Until recently, wealth data had not been collected in the United States for long enough to measure both parents' and offspring's wealth at mid- to late-life. Prior evaluations of intergenerational wealth mobility therefore had to rely on measures of wealth outcomes of offspring when they were, on average, only in their early 30s (Conley and Glauber 2008; Mulligan 1997) or late 30s (Charles and Hurst 2003). As these authors acknowledge, assessing child wealth at older ages and at the same ages for parents and children would be preferable. In particular, assessing child wealth at such early age likely downwardly biases estimates of intergenerational correlations, a phenomenon known as life-cycle bias. Thus, an additional contribution of our analysis is that we use the latest available data from the Panel Study of 
Income Dynamics (PSID) to estimate two-generation persistence in wealth on a sample of parent-child pairs that spans a larger age range in the second generation.

\section{Longer-term persistence of family wealth: Multigenerational associations}

Understanding how wealth is passed down through family lineages requires understanding which ancestors' wealth contributes to an individual's wealth position. Previous studies that have estimated two-generational associations in wealth privilege the notion of investments and direct transfers from parents to children. While, in most cases, parents are likely to make the biggest investments in children's future, assuming that the transmission of resources between family members occurs only from parents to children is an overly restrictive view of family support networks. For example, Hall and Crowder (2011) argue that individuals may benefit from the wealth of their extended family, including grandparents, and find that average wealth in an individual's extended family facilitates the transition to homeownership, net of individuals' own wealth.

The dearth of evidence on wealth and multigenerational associations is increasingly problematic in the context of demographic shifts in the U.S.: declines in fertility limit the number of offspring in which parents and grandparents invest; increased longevity prolongs the contact between older and younger generations; and declines in time spent married increases the importance of extended family networks, including grandparent-grandchild ties (Swartz 2009; Bengtson 2001). Grandparents are often heavily involved in children's lives; about 10 percent of American children live with at least one grandparent (United States Census Bureau 2017), and about one quarter of children under age 5 are in a regular childcare arrangement with a grandparent as caregiver (Laughlin 2013). Grandparents are also available far beyond early 
childhood. Today, U.S. grandparents are expected to overlap with their first grandchild, on average, by about 30 years (Leopold and Skopek 2015).

As multiple generations overlap and as families diversify, it becomes increasingly inappropriate to assume that all relevant intergenerational wealth transmission can be captured by the parent-child dyad. Grandparents may contribute to investments made in early adulthood, such as post-secondary education, purchase of a first home, and weddings, or they may bequeath wealth directly to their grandchildren. Increasing life expectancy and decreasing fertility rates imply that wealth transfers now occur at later ages, among fewer recipients, and may skip one generation. The potential for "generation-skipping" wealth is one reason to expect associations in wealth between the grandparent and the grandchild generation even conditional on the wealth of the parent generation (Mare 2011).

Recent research has observed three-generational influences of education, family income, and occupation in the U.S. and other industrialized nations (Chan and Boliver 2013; Hertel and GrohSamberg 2014; Wightman and Danziger 2014), although others find that the direct effects of grandparental characteristics are weak or conditional (Jæger 2012; Warren and Hauser 1997). Evidence on the multigenerational influence of family wealth, on the other hand, is so far limited to the Scandinavian context. Hällsten and Pfeffer (2017) show that, even in egalitarian Sweden, grandparental wealth exerts sizeable effects on their grandchildren's educational achievement, net of parental wealth. Yet, also in the Swedish context, the association between grandparental and grandchild wealth, conditional on parental wealth, is weak and imprecisely estimated (Adermon, Lindahl, and Waldenström 2016). By contrast, Boserup et al. (2014), using Danish data, report that a ten percentile increase in grandparental wealth is predicted to increase grandchild wealth by one percentile, conditional on the wealth of the middle generation. 
Here, we present the first estimates of the multigenerational persistence of family wealth for the United States. Our analyses report lineage correlations between parents and children and between grandparents and grandchildren. We also estimate the portion of the grandparentgrandchild association that is independent of the wealth of the intermediate (parent) generation. By doing so, we can reveal wealth persistence within family lineages that has been obscured in two-generation models.

\section{Channels of intergenerational wealth transmission across the life-course}

Many mechanisms may contribute to inter- and multigenerational similarity in wealth positions. We discuss and evaluate five that we believe are likely to be particularly important: bequests and gifts, educational attainment, marriage, homeownership, and business ownership. For the latter four channels, we remain agnostic about the specific underlying process by which family wealth is associated with the wealth of descendants. Offspring education, marriage, homeownership, and business ownership may each be facilitated by parental wealth in part through transfers - as captured by measures of bequests and gifts. However, these channels of transmission may also take effect through more indirect processes. Family wealth may, for example, provide safety nets for investments in human capital, business opportunities, and housing; social capital in the form of access to wealthy peers and potential marriage partners; access to high-quality neighborhoods and schools that facilitate the development of human, social, and cultural capital; or cultural models of investment behavior and preferences. We also recognize that the channels of transmission we highlight here will not capture all possible pathways linking wealth attainment across generations. For example, our models are not 
equipped to investigate the role of the cultural transmission of attitudes toward savings or portfolio allocation.

Among our five proposed key channels of transmission, we first consider the role of direct transfers through gifts, also called inter-vivos transfers, and bequests. Bequests and transfers are extremely unequally distributed and have been estimated to account for a little over half of aggregate net worth in the United States (Gale and Scholz 1994; Piketty 2014). Using Swedish data, Adermon et al. (2016) find that inheritances and gifts explain the majority of the intergenerational correlation in wealth. Direct transfers are thus a likely contributor to the intergenerational rigidity of the wealth structure.

Although gifts and bequests may generate large instantaneous wealth gains, family wealth may contribute even more to offspring wealth position via earlier investments and interventions that appreciate over a longer period. Family wealth is associated with a host of outcomes for the offspring generation — their education, homeownership, marriage, and self-employment — that are in turn associated with offspring's own ability to further accumulate wealth. Prior research has documented strong associations between parents' wealth and their children's educational outcomes, and education in turn facilitates wealth accumulation, through the achievement of higher incomes and potentially even net of it (as reviewed in Killewald, Pfeffer, and Schachner 2017). Although the mechanisms responsible for the residual association between education and wealth net of income are not established, one potential way education may benefit wealth accumulation is by shaping financial decision-making. For example, net of income, education is positively associated with ownership of stocks and other high-return assets (Hanna, Wang, and Yuh 2010; Kim et al. 2012; Hurst, Luoh, and Stafford 1998; Keister 2004). Thus, education may be a key channel for the transmission of wealth across generations. Parental and extended-family 
wealth are also associated with homeownership (Hall and Crowder 2011; Spilerman and Wolff 2012; Charles and Hurst 2002), and homeownership is in turn associated with greater subsequent wealth (Killewald and Bryan 2016). Since low-income couples cite a lack of financial resources as one reason to delay marriage (Edin and Kefalas 2005; Smock, Manning, and Porter 2005), parental wealth, including assistance with wedding costs, may speed transitions to marriage; marriage is associated with faster subsequent wealth growth (Zagorsky 2005). Finally, entry into self-employment is facilitated by parents' wealth (Dunn and Holtz-Eakin 2000); selfemployment is in turn associated with greater net worth (Altonji and Doraszelski 2005; Menchik and Jianakoplos 1997). While our focus is on business ownership rather than self-employment, these findings suggest that parents' wealth may facilitate the acquisition of business assets, which may in turn generate future wealth.

These channels likely differ in importance across offspring's life course. Investments in education are most central through adolescence and early adulthood, transitions into homeownership and marriage tend to occur soon after, business assets may be acquired either in early adulthood or later in life, while bequests are typically received in later adulthood, at least when they come from parents. This points to the possibility that grandparental bequests will play a larger role in the three-generation transmission of wealth than parental bequests do in the twogeneration transmission of wealth: Grandparental bequests occur earlier in children's lives and may therefore, unlike parental bequests, have similar cumulative effects on children's own wealth accumulation as other early-adulthood channels. Although data limitations prevent a comprehensive evaluation of the mechanisms responsible for the association between grandparent and grandchild wealth net of parent wealth, we provide suggestive evidence on this point in our analyses. 
Our analyses are not designed to estimate the unique causal mediating role of each of the proposed channels of transmission. Our list of channels of transmission is not exhaustive; if omitted channels are correlated with the included channels, the effects of the included channels may be overstated. Furthermore, the causal ordering of offspring wealth and the channels of transmission is unclear: our models assume, for example, that parental wealth facilitates offspring marriage, which in turn facilitates offspring wealth, but offspring marriage is also the result of offspring's own wealth (Schneider 2011). Therefore, our analyses are descriptive and follow a demographic approach.

In summary, the cumulative nature of wealth dictates an analytic approach that (1) explicitly considers specific life course events and transitions as channels of wealth transmission whose influence cumulates over time and (2) expands our view of relevant kin beyond the parent-child dyad, in particular to grandparents. Since prior research has documented large racial differences in wealth holdings (Oliver and Shapiro 1996), our analyses also pay attention to differences in the intergenerational transmission of wealth by race, as well as other demographic characteristics.

\section{DATA}

The Panel Study of Income Dynamics (PSID) follows a genealogical design that makes it ideal for intergenerational analyses: Children born to PSID households eventually become PSID respondents themselves as they form their own households. The PSID is the only nationally representative panel study that has been in the field long enough to include both a second and a third generation of adult survey respondents (Pfeffer 2014). The PSID has collected information on home values since its inception in 1968 and detailed information on families' assets, which 
allows the calculation of a family's net worth, every five years from 1984 until 1999 and every wave since then. Our main wealth measure is family net worth, which is the sum of all financial assets, real assets, and home equity, minus any financial obligations. The PSID wealth measures compare favorably to those of the Survey of Consumer Finances (SCF), often considered the gold standard among wealth surveys, attesting to the high validity of the former (Pfeffer et al. 2016; Bosworth and Smart 2009). One exception is a lack of coverage of the very top of the wealth distribution in the PSID, although the PSID does contain many multi-millionaires (no topcoding).

For the two-generational analyses, we take advantage of the earliest (1984-1989) and latest (2013-2015) wealth data collected in the PSID (Panel Study of Income Dynamics 2017), spanning three decades and including over a decade more wealth data than prior contributions that assessed wealth correlations based on the PSID. The full analytic sample contains 4,608 individuals aged 25-64 in 2013 and their parents, aged 25-64 in 1984. We link children to their biological or adoptive parents and grandparents using PSID's family identification mapping system (FIMS). For parents who do not live in the same household in 1984, for instance because they are divorced, we sum the net worth of parents if they are both observed in separate households ( 5 percent of the weighted sample). Where only the mother (19 percent) or the father (3 percent) is observed, we take her/his household net worth as the sole indicator of parental wealth. ${ }^{2}$

For the multigenerational analyses, we draw on two different samples with complementary strengths. In Sample A, we rely on grandparents' wealth reports from 1984 and 1989, the first

\footnotetext{
${ }^{2}$ One could instead impute the net worth of the missing parent, but we are not convinced that doing so is preferable, since the missing parent may be genuinely missing from the child's life and therefore should not count towards that child's wealth background. However, analyses that impute the wealth of a missing parent produce similar results (see Online Appendix, Table C.1).
} 
survey year in which the PSID included a full asset module $(\mathrm{N}=2,180)$. This allows us to use a net worth measure for grandparents that has been collected the same way as for parents and children. However, there are two important limitations. First, since we observe grandparents' and parents' wealth in the same survey year, there are large differences in the ages at which we observe grandparental and parental wealth. Second, this sample potentially suffers from mortality and frailty bias, since we only observe grandparents who are still alive in 1984 and still live in independent households. Direct multigenerational associations might be stronger when grandparents and grandchildren co-reside, downwardly biasing our estimates, but also stronger when grandparents survive more years overlapping with their grandchildren, upwardly biasing our estimates. Frailty and survivorship bias may also make our sample of grandparents more homogeneous in wealth levels, which will downwardly bias our estimates in the presence of measurement error in reports of grandparental wealth (see Solon 1992). Ideally, we would instead measure grandparents' wealth much earlier and at similar ages to the following generations.

A second multigenerational sample accomplishes that by observing grandparents in the first PSID survey years and using home values as a proxy for net worth, with the home values of renters set to zero. The principal residence is typically the largest asset in U.S. households' gross wealth portfolios (Wolff 2016). After testing the validity of this proxy measure, in Sample B we measure grandparents' self-reported home values in 1968 and 1969 and relate them to the home values of parents in 1984 and 1989 and of children in 2013 and $2015(\mathrm{~N}=2,532)$.

To reduce measurement error, we average wealth measures across two adjacent measurement points (2013 and 2015 for the offspring generation, 1984 and 1989 for the parents and grandparents, and 1968 and 1969 for the home values of grandparents). All dollar values are 
adjusted for inflation and expressed in 2015-\$. Our main results do not adjust wealth for family size, but models based on wealth measures adjusted by the square root of family size yield virtually identical results (see Online Appendix, Table C.1).

In our models that assess the role of the five channels of wealth transmission presented above, we report the percent decrease in the wealth association observed when each indicator is added to the regression model as the sole transmission channel and when added jointly. We tested a variety of measures of each channel (see Online Appendix, Table C.3) and report results for the best-performing measure for each channel — the measure that explained the highest fraction of the two-generational net worth association. Each indicator is measured for children in 2013 as a mediator of the two-generational wealth correlation, and for children in 2013 and parents in 1984 as mediators of the three-generational wealth correlations.

For gifts and bequests, we draw on a survey question, asked in each wealth wave of the PSID, on whether the family has received any large gifts or inheritances of over $\$ 10,000$ and, if so, their value (up to three mentions). We cumulate this information across all waves to approximate the total value of gifts and bequests ever received by children and parents and use the inverse hyperbolic sine (IHS) transformation to retain values of zero (alternative specifications tested: indicator for ever having received a substantial gift/inheritance; indicator for having received an inheritance in the last calendar year'; IHS-transformed value of gifts/inheritances received in the last year; and indicators of parental and grandparental death ${ }^{4}$ ).

\footnotetext{
${ }^{3}$ This indicator identifies inheritances received in all PSID waves since 1988, does so without imposing a lower limit, and excludes gifts. However, this survey item only captures bequests that occurred during the last year and therefore fails to capture a contiguous period of potential bequest receipt since PSID's switch to biennial interviewing in 1997. Also, we are forced to use measures from 1988 and 1989 as parental mediators (instead of 1984 as for the other mediators).

${ }^{4}$ The idea is that parental (and grandparental) deaths are a necessary condition for a bequest to occur. We create three categories: zero, one, or two (or more) parental (or grandparental) deaths recorded.
} 
Education is measured as the highest educational degree attained: less than high school, high school, some college, bachelor's, and post-graduate degree (alternative specifications tested: years of education; binary for college completion). For marital status, we use an indicator for being currently married (alternative specifications tested: whether ever married; total number of years married, based on the PSID marital history data). Business ownership is measured with an indicator for any current business assets. ${ }^{5}$ For homeownership, we construct a measure of the total number of years spent in homeownership to date as a share of the number of years in which we observe homeownership status (alternative specifications: current homeowner status; whether ever a homeowner).

In the two-generation models, we control for offspring age in 2013 and parental age in 1984 as well as their squared terms. In the multigenerational models, we additionally control for grandparental age (and age squared) in 1984 in the sample based on their net worth report and age (and age squared) in 1968 in the sample based on their home values. For the parental generation, we average maternal and paternal age if both are observed, and likewise for the grandparental generation.

To analyze race difference in the intergenerational transmission of wealth, we use the firstmentioned race reported by offspring to assign family race and distinguish non-Hispanic whites from non-Hispanic African-Americans. The PSID's oversample of African-American households facilitates these comparisons, but the sample size does not allow us to generate meaningful estimates specific to mixed-race families or other racial or ethnic groups. The average intergenerational wealth transmission that we estimate for each subgroup may therefore include substantial variation by ethnicity and nativity.

\footnotetext{
${ }^{5}$ Ownership of business assets is collected only in the years in which wealth data are collected, so we cannot construct a lifetime measure of years of business ownership.
} 


\section{METHODS}

To assess relative intergenerational mobility in wealth we estimate age-adjusted rank-rank slopes based on the following regression:

$$
\operatorname{rank}_{c}=\lambda_{0}+\lambda_{1} \operatorname{rank}_{p}+\lambda_{2} A g e_{c}+\lambda_{3} A g e_{c}^{2}+\lambda_{4} A g e_{p}+\lambda_{5} A g e_{p}^{2}+\epsilon_{c}^{\prime}
$$

with child's wealth $\left(\operatorname{rank} \mathrm{W}_{c}\right)$ and parental wealth $\left(\operatorname{rank} \mathrm{W}_{\mathrm{p}}\right)$ as the percentile rank in their respective weighted net worth distributions and age and age squared as adjustments for both the child $\left(\mathrm{Age}_{\mathrm{C}}\right)$ and parent generation $\left(\mathrm{Age}_{\mathrm{P}}\right)$. This specification allows us to assess the full distribution of wealth, since it easily accommodates cases of zero wealth and net debt. Also, the rank slope coefficient $\left(\lambda_{1}\right)$ is insensitive to differences in the marginal distributions across groups (Chetty et al. 2014; Jäntti and Jenkins 2015) and therefore easily comparable across groups. ${ }^{6}$ The rank slope is therefore a measure of relative mobility like those used in much prior research that assesses the social fluidity of societies (e.g. Erikson and Goldthorpe 1992).

To study similarity in wealth across three generations, we first re-estimate the twogenerational association (equation 2) based on each of the multigenerational samples. We assess the validity of these samples by comparing the resulting estimates of two-generational associations to our main estimates based on the larger two-generation sample. Next, we compare these two-generational rank slopes to unconditional rank slopes for grandparents, replacing parental wealth and age with grandparental wealth and age in equation 1 . These models estimate the extent of wealth similarity between grandparents and grandchildren, ignoring the parent generation. Finally, we estimate the association between grandparental wealth $\left(\operatorname{rank} \mathrm{W}_{\mathrm{gp}}\right)$ and

\footnotetext{
${ }^{6}$ These features make rank-rank slopes preferable to elasticities (based on log-transformed variables) for our analytic purpose. But since most prior research on intergenerational mobility reports elasticities, we provide those estimates in the Online Appendix (Table C.1). There, we also show that our results are substantively similar when we estimate intergenerational correlations based on wealth ranks drawn within age groups.
} 
children wealth while taking into account parental wealth, i.e.

$$
\begin{aligned}
\operatorname{rank}_{c}= & \mu_{0}+\mu_{1} \operatorname{rank}_{p}+\mu_{2} \operatorname{rank}_{g p}+\mu_{3} A g e_{c}+\mu_{4} A g e_{c}^{2} \\
& +\mu_{5} A_{g e} e_{p}+\mu_{6} A g e_{p}^{2}+\mu_{7} A g e_{g p}+\mu_{8} A g e_{g p}^{2}+\epsilon_{c}^{\prime \prime}
\end{aligned}
$$

where $\mu_{2}$ indicates the extent of wealth similarity between grandparents and grandchildren that is not explained by the wealth position and age of the parental generation. In other words, it is the direct association between grandparents and grandchildren, net of parental wealth as a mediator. This allows us to assess whether a sequence of two-generation associations adequately captures the multigenerational association in wealth.

Finally, to assess the contribution of each of the five channels of transmission that we hypothesized to underlie intergenerational wealth correlations - gifts and bequests, education, marriage, homeownership, and business ownership — we enter controls for these characteristics into equations (2) and (3) and observe the degree to which they mediate, separately and jointly, intergenerational correlations (see Online Appendix A for a detailed description how this approach differs from prior work by Charles and Hurst (2003)). For the mediation of the twogenerational (parent-child) correlation, we control for children's receipt of gifts and bequests, educational attainment, homeownership, marital status, and business ownership, each of which is measured in 2013, and observe the percent reduction in the correlation when these controls are introduced. For the assessment of mediation of the three-generation (grandparent-child) correlation, we additionally control for the same measures of the parents' characteristics, measured in 1984.

All of our analyses are weighted by the family weight of the parents (averaged across the two measurement points), and standard errors are clustered by the original sample family (grandparent). Unweighted results are similar (see Online Appendix, Table C.1). All wealth 
measures provided by the PSID are already imputed; we imputed the remaining and very few missing values on our mediator variables (separately for the two- and three-generational samples) using the Stata $m i$ command.

\section{RESUlts}

\section{Descriptives}

Descriptive statistics for our main analytic samples are displayed in Table 1. For our multigenerational analysis, we consider the sample based on home values the main sample. As discussed before, the latest PSID data allow us to capture the wealth of children and parents at more similar and higher ages than prior research: the mean age at which we observe parents in 1984 is 43.4 years and 44.5 years for children in 2013 . Half of the offspring are observed during their peak time of wealth accumulation, between 45 and 64 years of age. The close similarity of mean ages across two generations protects our estimates of two-generational correlations against life-cycle bias.

However, some differences in mean ages re-emerge in our three-generational sample. As one would expect, the requirement to additionally observe the wealth of grandparental households restricts our sample to somewhat younger children and parents (mean ages 37.0 and 35.2, respectively) than grandparents (46.7). The difference is even more pronounced in the sample that requires the observation of grandparental wealth in 1984 (average grandparental age of 61.6). More than 80 percent of the offspring in our main three-generational sample are observed between the ages of 25 and 44. As we show below, the assessment of wealth persistence across two generations rises with age, so the youth of our multigenerational sample may also underestimate multigenerational wealth transmission, making our estimates of multigenerational associations conservative. 
[Table 1 about here]

Mean net worth decreased from $\$ 352,727$ in the parent generation to $\$ 330,022$ in the child generation. Children's average wealth was already lower than their parents' wealth before the Great Recession: Offspring mean wealth was $\$ 327,137$ in $2005-2007$, before the large-scale asset destruction brought about by the collapse of the housing and stock markets. The share of offspring with zero or negative net worth increased from 14.0 percent pre-recession to 16.8 percent after the recession, compared to less than 6 percent of parents in 1984-1989. Average net worth for both the child and the parent generation are lower in the three-generational sample since, as mentioned above, they are assessed at earlier ages, while the net worth of grandparents in 1984 is much higher than that of parents and children.

In the two-generational sample, the mean home value in the child generation, including nonowners as $\$ 0$, is $\$ 175,493$ and higher than in the parent generation $(\$ 147,149)$, despite the fact that homeownership is more widespread among the parent generation ( 82.5 percent) than the child generation (69.0 percent). In our three-generational sample, we observe similar gaps in homeownership rates between children and parents, very similar homeownership rates between parents and grandparents, and average home values that are similar for the child and parent generations and lowest for the grandparent generation.

\section{Two-Generational Wealth Correlations}

Table 2 shows the estimated intergenerational rank correlations in net worth. We find a rank slope of 0.39 , which means that an advantage of 10 percentiles in the parent generation is associated with an advantage of 3.9 percentiles in the child generation. We also observe that the intergenerational wealth correlation rises with age, from 0.33 among offspring aged 25-34 to a 
third higher, 0.44 for offspring aged 55-64 (this difference is statistically significant at $\mathrm{p}<.05$ ). This pattern suggests that estimates of rigidity in the wealth structure should ideally be based on measures of wealth attainment during older adulthood and when generations are similar ages. In the following two-generational analyses, we therefore focus on the group of children aged 45 to 64, for whom the estimated rank slope is 0.41 , compared to 0.36 among those aged $25-44$.

[Table 2 about here]

To our baseline estimate of intergenerational wealth correlation, we add two important observations. First, a mobility table for children aged 45-64 (see Online Appendix, Table C.2) confirms prior evidence that intergenerational wealth persistence in the United States is particularly strong at the top and bottom of the wealth distribution (see also Charles and Hurst 2003; Conley and Glauber 2008). For example, 42 percent of children from the highest parental wealth quintile also end up in the highest wealth quintile themselves (total net worth of $\$ 631,000$ or more), and 39 percent of children in the bottom quintile of the parental wealth distribution remain there as adults, holding less than $\$ 15,000$ in net worth.

Second, shifts in the wealth distribution between the parent and child generation imply that the stakes of wealth mobility have increased. While a move from the $80^{\text {th }}$ to $90^{\text {th }}$ percentile implied a wealth advantage of less than $\$ 340,000$ (in 2015\$) among the parents in this sample, the same move corresponds to a wealth advantage of more than $\$ 563,000$ for their children.

\section{Multigenerational Associations in Wealth}

We next turn to the first of our two core research questions: whether the role of prior generation wealth for current wealth positions has been understated by considering only transmission from parents to children, rather than three generations. In Table 3, we report the 
results of our multigenerational analyses that, as described above, are based on two different measures of grandparental wealth and two different resulting samples. We begin by discussing rank slopes in self-reported net worth (Sample A).

\section{[Table 3 about here]}

Recall that our estimate of the two-generational net worth correlation, using the full sample of offspring ages 25-64, is 0.39 (column 1; see also Table 2). When we re-estimate the same association, restricted to the three-generational sample, the association is lower, 0.32 . At least some of this difference is likely due to the younger ages of parents and children in our threegenerational samples. That is, while we are able to successfully eliminate life-cycle bias in our main two-generational analyses reported above, it re-emerges in our three-generational samples, and we do not have sufficient sample size in the three-generation samples to restrict the sample to older offspring. The share of the grandparent-grandchild association that is mediated by parental wealth may also vary with age. The direct association between grandparents and grandchildren could fade with age as grandparents die and grandchildren are no longer exposed to their influence. On the other hand, grandparental wealth could become more important with age if grandparents bequeath directly to their grandchildren. At the same time, the strength of the two-generational associations, and therefore of the indirect pathway via parental wealth, is also changing with age. The net bias of our estimate of the share of the three-generation association that passes through the middle generation is unclear. We believe that our analysis provides the best estimate possible of the extent to which the association between grandparent and grandchild wealth is independent of parental wealth, but we also recognize that future research is needed to test the robustness of our results across the life cycle of the grandchild. 
The grandparent-grandchild rank slope is $73 \%$ the size of the parent-child rank slope $(0.23$ compared to 0.32). If we were to predict the wealth attainment of children from the wealth position of their grandparents, we would on average expect an increase of 2.3 percentiles in the child generation for every decile increase in the grandparental generation.

Most importantly for our research question, only about half of this three-generational association goes through the wealth attainment of the parent generation $(0.12$ versus 0.23$){ }^{7}$ Even after accounting for the shared association with parental wealth, grandparental wealth is a significant predictor of grandchild wealth, both substantively and statistically. ${ }^{8}$ The explained variance in offspring wealth attainment increases by 12 percent when, in addition to parental wealth $\left(\mathrm{R}^{2}=0.147\right)$, we consider grandparental wealth $\left(\mathrm{R}^{2}=0.164\right){ }^{9}$

To overcome the limitation of Sample A that grandparents' wealth is assessed at a different and much higher average age than parents' or offspring's, we now turn to our main analysis that relies on home value as an indicator of wealth (Sample B). First, and importantly, we observe that the two-generational rank slope in home values (column 1) is quite similar to the two-

\footnotetext{
${ }^{7}$ Assessments of multigenerational associations are generally vulnerable to bias from measurement error in the parent generation: Two-generational influences that would be captured by less-error parental measures can instead accrue to the multigenerational association. Re-estimating the last presented model based on single-point wealth measures (1984 and 2013) yields practically the same conditional multigenerational association (0.124) as our main analysis that is based on wealth measures with reduced measurement error (through the averaging across two survey waves). This finding is encouraging since it suggests that classical measurement error as partly captured through the averaging of wealth measures does not substantially bias our estimate of the conditional multigenerational association. Similarly, concerns about potential upward bias in the conditional multigenerational association that could, in principle, arise from lower wealth measurement error for grandparents compared to parents based on the fact that we are measuring grandparental wealth at higher ages than parental wealth (see Adermon et al. 2016) are not borne out by the data. In fact, assessing parental wealth at later ages (in 2013/2015 instead of 1984/1989) suggests a somewhat larger conditional multigenerational association.

${ }^{8}$ If one assumes that life-cycle bias impacts the multigenerational association presented here in the same way that it impacts the two-generational estimates, one can use the observed difference in the two-generational estimate (column 1 versus 2$)$ to compute an adjustment factor $(=1.22)$ and apply it to the multigenerational association (column 3), raising it from 0.23 to 0.28 . If one were willing to additionally - and even more heroically - assume that the observed life-cycle bias also applies in the same way to the G1-G2 and G2-G3 associations, the conditional multigenerational net worth association (column 4) would be raised from 0.12 to 0.15 .

${ }^{9}$ We tested for interactions between parental and grandparental wealth but found few statistically significant interactions and they were inconsistent across the different multigenerational samples.
} 
generational rank slope in net worth (0.37 versus 0.39$)$, implying that home values alone may

provide a valid proxy measure for the assessment of intergenerational wealth correlations. We consider this an important finding since home values are often more readily accessible measures that could be used in research based on a broader range of data. Measures of home equity (home value minus mortgages) yielded somewhat weaker associations (see Online Appendix, Table C.1). ${ }^{10}$

Importantly, the striking similarity in the intergenerational correlations based on net worth versus home values extends to the multigenerational case: the unconditional multigenerational association in this sample is 0.21 , compared to 0.23 in Sample A, and the conditional association is 0.11 , compared to 0.12 in Sample A. The explained variance in wealth attainment based on grandparental home values is 10 percent higher than that explained by parental home values alone. Our conclusions about the multigenerational transmission of net worth offered above thus hold in precisely the same way for the multigenerational similarity in home values. Furthermore, our estimates of multigenerational wealth correlations are not very sensitive to whether wealth from both (rather than just one) grandparental lineage is included, as shown in Online Appendix B. In the same sensitivity analyses, we show that the estimated multigenerational associations, both conditional and unconditional, are similar regardless of whether the paternal or maternal lineage is used. ${ }^{11}$

\footnotetext{
${ }^{10} \mathrm{We}$ assessed whether the estimated correlations in home values are driven by the intergenerational persistence of homeownership. Models restricted to homeowners in all generations yielded a two-generational rank slope of 0.32 instead of 0.35 and a conditional three-generational rank slope of 0.16 instead of 0.11 , indicating that correlations in home values are not simply reflections of familial histories of homeownership.

${ }^{11}$ Features of the PSID inhibit a similar assessment of the role of paternal versus maternal wealth: (1) the PSID defines net worth as a property of families rather than of individuals, so it is not possible to assess the relative influence of maternal versus paternal wealth for co-residential parents; (2) for parents who do not co-reside, the PSID follow rules are such that net worth measures are only available for both parents about half the time (when the nonresidential parent is a member of an original PSID family). Therefore, to assess whether the intergenerational transmission of maternal and paternal wealth differ, future research will need to make use of data that include individual measures of wealth, such as those collected in the German Socio-Economic Panel (SOEP).
} 
Overall, our complementary approaches to address different data challenges in this section leave us with a greatly consistent answer: the three-generational correlation in wealth is about two thirds the size of the parent-child correlation, and only half of that multigenerational correlation is explained by the wealth position of the middle generation. This implies that prior estimates of the persistence of wealth across generations within a family, based on only two generations, have understated the importance of family wealth position for own wealth outcomes.

\section{Channels of Intergenerational and Multigenerational Wealth Transmission}

In this section, we examine the importance of five channels of intergenerational wealth transmission underlying the two-generational wealth associations, with a supplementary discussion of transmission across three generations: (1) gifts and bequests, (2) educational attainment, (3) marriage, (4) homeownership, and (5) business ownership. We report results for the older age group (aged 45-64), which is particularly important to allow the net worth effects of these channels to manifest. The results are descriptive rather than causal, continuing our demographic approach, but they provide suggestive evidence on the relative contributions of different pathways to the intergenerational transmission of advantage.

As shown in the first section of Table 4, the cumulative amount of gifts and inheritances over $\$ 10,000$ received to date explains only 12 percent of the observed intergenerational association in net worth. Assessing the size of these transfers only among those who received them does not explain appreciably more of the association (13 percent, see Online Appendix, Table C.3). One feasible explanation is that bequests are in fact concentrated at the top of the wealth distribution and the modal impact of parental death is not one of a pronounced increase in 
children's relative net worth position.

[Table 4 about here]

In contrast to the relatively small role of gifts and bequests, accounting for the child's highest degree received explains a quarter of the intergenerational wealth association. The attainment of a college degree alone mediates close to a fifth of the association (see Online Appendix, Table C.3). Housing tenure, marital status, and business ownership mediate 28, 14, and 8 percent of the two-generational association in net worth, respectively. Thus, gifts and bequests mediate a notably smaller share of the two-generational persistence of wealth than both education and homeownership. Together, all five indicators of our hypothesized channels of wealth transmission account for 60 percent of the two-generational association in wealth. The subordinate role of gifts and bequests is reflected in the fact that, even without their consideration, we still account for 56 percent of the two-generational association in wealth.

In the next column of Table 4, we repeat the analysis for the mediation of twogenerational correlations in home values — instead of net worth — excluding homeownership as a mediator. Except for the smaller mediating role of business ownership in this analysis, we observe quite similar findings. Our earlier finding that home values are a powerful proxy measure to describe the intergenerational persistence of wealth can thus be extended to include their role as a strong proxy measure when it comes to assessing the mediating role of the hypothesized transmission channels.

This finding is helpful because it allows us to pursue a tentative analysis of channels of multigenerational wealth transmission, relying on our main multigenerational sample that is based on grandparental home values. Even relying on home values as proxy measures of wealth, the sample in which we can observe all three generations at older ages is quite small $(\mathrm{N}=359)$. 
For this reason, we interpret the results of the channels of transmission for the multigenerational associations as providing suggestive evidence only. In these models, we additionally condition on parents' values of these same channels measured in 1984. Minimally, the multigenerational findings are not inconsistent with the two-generation results regarding the modest role of transfers: the fraction of the conditional grandparent-grandchild association explained by parents' and children's receipt of transfers is smaller than for any of the other channels of transmission. This is important since, as described above, the generational spacing between grandparents and grandchildren could, in principle, give generation-jumping bequests a more exposed role for wealth attainment and the multigenerational transmission of advantage.

Together, our results suggest that channels of transmission that are indirect but tend to take place or at least begin earlier in the life course have a greater role in wealth persistence across two generations than gifts and bequests, which typically occur later in life. This result also suggestively holds across three generations. In particular, the limited role of gifts and bequests in even the multigenerational transmission of wealth is notable since grandparents provide these transfers at earlier ages of the child.

\section{Group Differences in Wealth Transmission}

We next consider the possibility of variation in the intergenerational transmission of wealth between men and women, whites and blacks, and before and after the Great Recession. In Table 5, we observe that the rank-slope correlation in wealth is very similar for men and women, across both two and three generations. The two-generational association in net worth (but not the threegenerational association in home values) was somewhat lower before the Great Recession than it is today. We find the largest differences in the intergenerational transmission of wealth by race. 
The two-generational correlation in wealth positions is only half as strong for African-Americans as for whites $(0.18$ versus 0.36$)$. These race differences were similar before the Great Recession (0.13 versus 0.32$)$. Multigenerational associations are similar by race, but the association for African-Americans is estimated imprecisely.

[Table 5 about here]

One possibility is that the low two-generational wealth correlation observed for AfricanAmericans is due to their underrepresentation at the top of the wealth distribution, where persistence is greatest. Figure 1 shows race-specific mobility patterns across the wealth distribution. For every decile of the weighted parental wealth distribution, we plot the average wealth percentile of the offspring (ages 45-64) of those parents, separately by race. The size of the marker is proportional to the weighted fraction of parents found in that decile. The figure visualizes the large racial gaps in parental wealth: the markers for African-American families are much larger at the bottom of the distribution than at the top, while the markers for white families are approximately equally sized across the wealth distribution. A full 41 percent of AfricanAmerican parents are found in the bottom decile of the wealth distribution, compared to only 7 percent of white parents. Second, the fitted line for African-Americans is shallower than the fitted line for whites, demonstrating weaker intergenerational persistence. However, the figure also highlights that, at each decile of parental wealth, the average wealth of African-American adult children falls below that of their white peers. Thus, our results indicate that the higher intergenerational correlation in wealth for whites than African-Americans is not exclusively due to African-Americans' severe underrepresentation at the very top of the distribution: Race differences in mobility appear across the wealth distribution. At the same time, they show that the greater mobility for African-Americans is not symmetric, but is dominated by greater rates of 
downward mobility. This is consistent with Conley and Glauber's (2008) finding that intergenerational reproduction at the top of the wealth distribution is stronger for white families, while intergenerational persistence at the bottom of the distribution is stronger for AfricanAmerican families. We can also observe this stark downward mobility in terms of the intergenerational persistence of home values (see Online Appendix, Table C.4.1): even among African-Americans whose parents owned homes with above-average values, the minority (42 percent) are themselves owners compared to 80 percent of whites with similarly-positioned parents.

[Figure 1 about here]

These patterns also hold for the multigenerational case (see Online Appendix, Table C.4.2): About half of the African-American grandparents in our sample were homeowners in 1968/1969, compared to 82 percent of white grandparents. Two generations later, rates of homeownership are higher for whites whose grandparents were not homeowners (56 percent) than for AfricanAmericans with grandparents owning homes with below- or even above-average values (40 and 50 percent, respectively).

We also explored variation by race in the mediating role of each channel of transmission (see Online Appendix, Table C.5). Overall, the five channels of transmission we consider explain a larger share of the two-generational association in wealth positions for African-Americans (68 percent) than for whites (52 percent), although this difference in relative terms is perhaps not surprising, given the substantially weaker baseline association for African-Americans. Education plays a leading explanatory role for both races, followed by homeownership. Future research is needed to further explore the causes of the race gap in the transmission of wealth position across generations and to investigate whether transmission channels operate differently by race. Our 
sample size is too small to explore race-specific channels of three-generational wealth transmission, but this is also a promising avenue for future research.

\section{CONCLUSION}

The distribution of family wealth is highly unequal, yet wealth's concentration across generations has received little scholarly attention. Furthermore, prior research studying the intergenerational persistence of wealth has largely borrowed the theoretical and analytical approach used to study intergenerational correlations in income, occupation, and education. We argue that, due to the cumulative nature of wealth, the study of intergenerational wealth mobility needs instead to be embedded in a long-term perspective that reaches forward to late adulthood to adequately measure wealth attainment and its intergenerational similarity, while simultaneously recognizing that later-life wealth is the result of transmission channels in early adulthood, including education, and of multi-generational transmission processes, including not only parents but also grandparents.

Using a sample of parent-child pairs measured at similar ages in middle adulthood, we estimate that, on average, a 10 percentile advantage in parents' wealth position is associated with a 4 percentile advantage in the child generation. Furthermore, we note that the rise in wealth inequality from the parent generation to the offspring generation implies increasing financial consequences of one's relative wealth position: family wealth becomes more important in absolute terms as the wealth distribution becomes more unequal.

Second, we provide the first-ever estimates of multigenerational correlations in the wealth position of U.S. families. Using multiple approaches designed to overcome data limitations, our findings are consistent: the persistence of wealth across three generation is about two-thirds the 
size of the parent-child wealth correlation, and about half of the grandparent-grandchild association flows through parental wealth. Thus, grandparental wealth is associated with grandchild wealth, net of parental wealth. This result reveals that prior estimates of the twogenerational persistence in family wealth have understated wealth rigidity within family lineages by failing to consider the independent role of grandparental resources. Our findings speak directly to exhortations in both the stratification and family demography literatures to consider families in broader perspective, recognizing the influence of kin other than parents on children's outcomes (Mare 2011; Bengtson 2001).

Third, we identify five channels through which wealth is transmitted across two and three generations and descriptively assess their relative importance: gifts and bequests, educational attainment, marriage, homeownership, and business ownership. We find that more than half of the two-generational transmission of wealth is explained by educational attainment and channels that typically emerge in early adulthood, especially homeownership, but also marriage and business ownership. Our finding that educational attainment and homeownership are the most important channels for intergenerational wealth transmission is consistent with prior evidence documenting large and rising wealth gaps in educational attainment (Conley 2001; Pfeffer Forthcoming), the importance of family resources for the transition to homeownership (Hall and Crowder 2011; Spilerman and Wolff 2012; Charles and Hurst 2002), and the effect of homeownership on subsequent wealth (Killewald and Bryan 2016). In contrast, gifts and bequests explain a small part of intergenerational wealth correlations. We considered that, because grandparental death typically occurs during grandchildren's earlier adulthood, bequests and gifts directly received from grandparents may weigh heavier in offspring's ultimate wealth attainment. We find no such evidence. Instead, our findings suggest that investigations of the 
reproduction of wealth across generations should pay at least as much attention to early-life, indirect investments by parents and grandparents in offspring, including educational attainment and homeownership, as to direct, later-life transfers, such as bequests. Future research might explore the role of other, even earlier, types of investments by parents, such as those to access advantageous neighborhoods, social capital, or cultural capital.

Of course, our analyses do not negate the possibility that some families provide exceptional advantage to their offspring by directly transferring large amounts of wealth, but our results suggest that, on average, direct transfers are not the primary channel through which wealth advantage is passed across generations.

Fourth, we assess heterogeneity in wealth correlations across select groups and periods. We document great similarity in wealth correlations between males and females as well as across a period marked by tremendous aggregate shocks, namely the recent Great Recession. In contrast, we find stark differences in wealth mobility between whites and African-Americans. Consistent with the findings of Conley and Glauber (2008), the association between parental and offspring wealth is weaker for African-Americans than for whites. Furthermore, we show that AfricanAmerican offspring have lower average wealth than their white peers at every decile of parental wealth. However, the channels of transmission we consider explain even more of the intergenerational association in wealth for African-Americans than for whites, and education and homeownership are the most important channels for both races.

What might account for the diminished intergenerational persistence for blacks compared to whites? As documented in Figure 1, we do not believe that our result is an artifact of AfricanAmericans' greater representation at positions in the wealth distribution where intergenerational persistence tends to be lower: the flatter association between parental wealth and offspring 
wealth holds across the distribution. Neither is the lower persistence for African-Americans the result of greater bidirectional fluidity. Instead, the weaker intergenerational wealth association among African-Americans is driven by their greater rate of downward mobility. In this way, the results are consistent with evidence that African Americans are disadvantaged at every stage of the status attainment process connecting social origins to adult outcomes (Blau and Duncan 1967) and receive lower wealth returns to their income and demographic characteristics (Altonji and Doraszelski 2005). Future research is needed to further probe the source of these disparities, but they are certainly consistent with enduring racial discrimination.

Lastly, our results are robust across multiple specification checks, such as adjusting our wealth measures for family size or averaging them across years, reducing concerns that our main results are attenuated by remaining measurement error. One specification test with broader implications is our finding that the value of a family's home is a very good proxy measure to study the questions addressed here. Our estimates of intergenerational correlations in home values, even without considering mortgages, replicate estimates based on net worth. And our assessment of the channels of wealth transmission can be similarly well approximated based on intergenerational correlations in home values rather than full-fledged net worth measures. Identifying home values as a potential proxy measure to assess intergenerational wealth correlations may open vast opportunities for future research using non-survey data sources such as the home value reports in the publicly available 1940 Census or estimates of home values provided by real estate companies, such as Zillow. Substantively, it may also promote a much closer consideration of the links and overlaps of the growing literatures on wealth, on one side, and on housing and neighborhoods on the other. Future research may seek to establish whether 
and to what extent the advantages and disadvantages flowing from housing wealth are genuine asset ownership effects or housing and neighborhood effects.

Our results also do not reveal substantial evidence of mortality or frailty bias: our estimates of multigenerational association in wealth, conditional on parental wealth or not, are similar regardless of whether we use the sample based on grandparents surviving until 1984 or the broader samples based on home values in 1968/69. Given that frailty and mortality bias may have offsetting effects, future research is needed to further explore under what circumstances patterns of co-residence and mortality at older ages bias estimates of multigenerational mobility.

As limitations and additional considerations for future research, we first note that the very wealthy are underrepresented in the PSID (Pfeffer et al. 2016; Bosworth and Smart 2009). Therefore, while our results describe the typical strength and channels of wealth transmission across the wealth distribution, patterns may be different for the very wealthiest American families. Due to small sample sizes, we were also not able to assess racial and ethnic differences in the patterns and channels of wealth transmission other than those between whites and AfricanAmericans. As the wealth attainment of other racial and ethnic groups, such as Latinos and Asians, gains more attention, research should attend to its intergenerational determinants, which may be quite different given the lower wealth position of immigrants' ancestors and the potential for reverse transfers. That is, transfers to their parents and remittances to their origin countries may limit immigrants' wealth accumulation and influence their wealth mobility in this country.

Second, we recognize that life-cycle bias may remain a concern for our multigenerational estimates. Patience and the further ageing of the PSID sample will eventually provide a remedy, potentially about a decade from now, just as our two-generation estimates provide a corrective to earlier two-generation analyses based on relatively young adult offspring. At older ages, the 
fraction of the grandparent-grandchild wealth association that is mediated by parental wealth may either increase or decrease. Until then, we consider our multigenerational findings to provide tentative estimates of the longer-term rigidity in the wealth distribution.

Third, we reiterate that our analyses of channels of transmission are descriptive, and for the three-generation analyses they are further based on a small sample. Future research is needed to determine the causal role of these and other channels of wealth transmission.

Fourth, future research could further incorporate the tenets of a genuine life course approach. As previously discussed, different channels of transmission may be more or less important for wealth accumulated at different points in offspring's life course. Furthermore, the wealth consequences of channels may depend on the timing at which these salient events - marriage, completion of schooling, purchase of a home, acquisition of a business, or receipt of a gift or bequest - occur. Analyses that engage the interdependence of events in multiple domains may also uncover how different channels of transmission reinforce one another across the life course and how each both promotes and is promoted by wealth. Last, the set of family members who are considered to potentially contribute to the wealth of future generations could be further expanded, either incorporating still-earlier generations or expanding laterally to include (great)aunts and (great)uncles.

Our description of the intergenerational persistence in wealth, its variation across the lifecourse and generations, and the underlying channels of transmission provide a comprehensive assessment of an understudied dimension of societal rigidity. Stratification research has begun to identify wealth as an important dimension of particularly large inequality. Our results caution that this inequality is bound to be replicated across generations. Our research leads us to be skeptical of the ability of future generations to share in economic prosperity by overcoming the 
disadvantages related to their wealth origins. If our analyses were to guide political measures to counteract this bleak outlook, we would stress our finding that inequalities in the opportunities tied to and constitutive of wealth emerge early in life. By the time large, direct, intergenerational wealth transfers occur, such as in the form of bequests, the beneficial effects of wealth have long been established and already materialized in offspring's own wealth attainment - these transfers are merely the cherry on top. 


\section{REFERENCES}

Adermon, Adrian, Mikael Lindahl, and Daniel Waldenström. 2016. "Intergenerational Wealth Mobility and the Role of Inheritance: Evidence from Multiple Generations." 10126. IZA Discussion Paper Series. Bonn, Germany: Institute for the Study of Labor. http://ftp.iza.org/dp10126.pdf.

Altonji, Joseph G., and Ulrich Doraszelski. 2005. "The Role of Permanent Income and Demographics in Black/White Differences in Wealth." Journal of Human Resources 40 (1): $1-30$.

Becker, Gary S., and Nigel Tomes. 1979. "An Equilibrium Theory of the Distribution of Income and Intergenerational Mobility." Journal of Political Economy 87 (6):1153-89. https://doi.org/10.1086/260831.

Bengtson, Vern L. 2001. "Beyond the Nuclear Family: The Increasing Importance of Multigenerational Bonds." Journal of Marriage and Family 63 (1):1-16. https://doi.org/10.1111/j.1741-3737.2001.00001.x.

Blau, Peter M., and Otis Dudley Duncan. 1967. The American Occupational Structure. New York: Wiley.

Boserup, Simon Halphen, Wojciech Kopczuk, and Claus Thustrup Kreiner. 2014. "Stability and Persistence of Intergenerational Wealth Formation: Evidence from Danish Wealth Records of Three Generations." http://www.columbia.edu/ wk2110/bin/WealthAcrossGen.pdf.

Bosworth, Barry, and Rosanna Smart. 2009. "Evaluating Micro-Survey Estimates of Wealth and Saving." CRR WP 2009-4. Chestnut Hill, MA: Center for Retirement Research at Boston College. http://papers.ssrn.com/abstract $=1368830$.

Chan, Tak Wing, and Vikki Boliver. 2013. "The Grandparents Effect in Social Mobility Evidence from British Birth Cohort Studies.” American Sociological Review 78 (4):66278. https://doi.org/10.1177/0003122413489130.

Charles, Kerwin Kofi, and Erik Hurst. 2002. "The Transition to Home Ownership and the BlackWhite Wealth Gap." Review of Economics and Statistics 84 (2):281-97. . 2003. "The Correlation of Wealth across Generations." Journal of Political Economy 111 (6):1155-82.

Chetty, Raj, Nathaniel Hendren, Patrick Kline, Emmanuel Saez, and Nicholas Turner. 2014. "Is the United States Still a Land of Opportunity? Recent Trends in Intergenerational Mobility." The American Economic Review 104 (5):141-47.

Conley, Dalton. 2001. "Capital for College: Parental Assets and Postsecondary Schooling." Sociology of Education 74 (1):59-72.

Conley, Dalton, and Rebecca Glauber. 2008. "Wealth Mobility and Volatility in Black and White." Washington, DC: Center for American Progress. https://www.americanprogress.org/issues/economy/report/2008/07/29/4662/wealthmobility-and-volatility-in-black-and-white/.

Dunn, Thomas, and Douglas Holtz-Eakin. 2000. "Financial Capital, Human Capital, and the Transition to Self-Employment: Evidence from Intergenerational Links.” Journal of Labor Economics 18 (2):282-305. https://doi.org/10.1086/209959.

Edin, Kathryn, and Maria Kefalas. 2005. Promises I Can Keep: Why Poor Women Put Motherhood before Marriage. Berkeley, CA: University of California Press.

Elder, Glen H., Jr. 1994. "Time, Human Agency, and Social Change: Perspectives on the Life Course." Social Psychology Quarterly 57 (1):4-15. https://doi.org/10.2307/2786971. 
Erikson, Robert, and John H. Goldthorpe. 1992. The Constant Flux: A Study of Class Mobility in Industrial Societies. New York: Oxford University Press.

Gale, William G., and John Karl Scholz. 1994. "Intergenerational Transfers and the Accumulation of Wealth." The Journal of Economic Perspectives 8 (4):145-60.

Hall, Matthew, and Kyle Crowder. 2011. "Extended-Family Resources and Racial Inequality in the Transition to Homeownership." Social Science Research 40 (6):1534-46. https://doi.org/10.1016/j.ssresearch.2011.07.002.

Hällsten, Martin, and Fabian T. Pfeffer. 2017. "Grand Advantage: Family Wealth and Grandchildren's Educational Attainment in Sweden.” American Sociological Review 82 (2):328-60.

Hanna, Sherman D., Cong Wang, and Yoonkyung Yuh. 2010. "Racial/Ethnic Differences in High Return Investment Ownership: A Decomposition Analysis." Journal of Financial Counseling and Planning 21 (2):44-59.

Hertel, Florian R., and Olaf Groh-Samberg. 2014. "Class Mobility across Three Generations in the U.S. and Germany." Research in Social Stratification and Mobility 35:35-52. https://doi.org/10.1016/j.rssm.2013.09.007.

Hertz, Tom, Tamara Jayasundera, Patrizio Piraino, Sibel Selcuk, Nicole Smith, and Alina Verashchagina. 2007. "The Inheritance of Educational Inequality: International Comparisons and Fifty-Year Trends." The B.E. Journal of Economic Analysis \& Policy 7 (2):Advances, Article 10. https://doi.org/10.2202/1935-1682.1775.

Hurst, Erik, Ming Ching Luoh, and Frank P. Stafford. 1998. "The Wealth Dynamics of American Families, 1984-94.” Brookings Papers on Economic Activity 1998 (1):267-337.

Jæger, Mads Meier. 2012. "The Extended Family and Children's Educational Success." American Sociological Review 77 (6):903-22. https://doi.org/10.1177/0003122412464040.

Jäntti, Markus, and Stephen P. Jenkins. 2015. "Income Mobility.” In Handbook of Income Distribution, edited by Anthony B. Atkinson and François Bourguignon, 2:807-935. Amsterdam: Elsevier.

Keister, Lisa A. 2004. "Race, Family Structure, and Wealth: The Effect of Childhood Family on Adult Asset Ownership.” Sociological Perspectives 47 (2):161-87. https://doi.org/10.1525/sop.2004.47.2.161.

Keister, Lisa A., and Stephanie Moller. 2000. "Wealth Inequality in the United States." Annual Review of Sociology 26:63-81.

Killewald, Alexandra, and Brielle Bryan. 2016. "Does Your Home Make You Wealthy?" RSF: The Russell Sage Foundation Journal of the Social Sciences 2 (6):110-28.

Killewald, Alexandra, Fabian T. Pfeffer, and Jared N. Schachner. 2017. "Wealth Inequality and Accumulation." Annual Review of Sociology 43. https://doi.org/https://doi.org/10.1146/annurev-soc-060116-053331.

Kim, Eun Jin, Sherman D. Hanna, Swarn Chatterjee, and Suzanne Lindamood. 2012. "Who among the Elderly Owns Stocks? The Role of Cognitive Ability and Bequest Motive." Journal of Family and Economic Issues 33 (3):338-52. https://doi.org/10.1007/s10834012-9295-2.

Laughlin, Lynda. 2013. "Who's Minding the Kids? Child Care Arrangements: Spring 2011." P70-135. Current Population Reports. Washington, DC: U.S. Census Bureau. https:/www.census.gov/prod/2013pubs/p70-135.pdf. 
Leopold, Thomas, and Jan Skopek. 2015. "The Demography of Grandparenthood: An International Profile.” Social Forces 94 (2):801-32. https://doi.org/10.1093/sf/sov066.

Mare, Robert D. 2011. "A Multigenerational View of Inequality." Demography 48 (1):1-23. https://doi.org/10.1007/s13524-011-0014-7.

Menchik, Paul L., and Nancy Ammon Jianakoplos. 1997. "Black-White Wealth Inequality: Is Inheritance the Reason?" Economic Inquiry 35 (2):428-42.

Mulligan, Casey B. 1997. Parental Priorities and Economic Inequality. Chicago, IL: University of Chicago Press.

Panel Study of Income Dynamics, public use dataset. 2017. Ann Arbor, MI: Produced and distributed by the Survey Research Center, Institute for Social Research, University of Michigan.

Pfeffer, Fabian T. Forthcoming. "Growing Wealth Gaps in Education.” Demography.

- 2008. "Persistent Inequality in Educational Attainment and Its Institutional Context." European Sociological Review 24 (5):543-65. https://doi.org/10.1093/esr/jen026.

—. 2014. "Multigenerational Approaches to Social Mobility: A Multifaceted Research Agenda." Research in Social Stratification and Mobility 35 (March):1-12. https://doi.org/10.1016/j.rssm.2014.01.001.

Pfeffer, Fabian T., Sheldon Danziger, and Robert F. Schoeni. 2013. "Wealth Disparities before and after the Great Recession." Annals of the American Academy of Political and Social Science 650 (1):98-123.

Pfeffer, Fabian T., Robert F. Schoeni, Arthur Kennickell, and Patricia Andreski. 2016. "Measuring Wealth and Wealth Inequality: Comparing Two U.S. Surveys." Journal of Economic and Social Measurement 41 (2):103-20. https://doi.org/10.3233/JEM-160421.

Piketty, Thomas. 2014. Capital in the Twenty-First Century. Translated by Arthur Goldhammer. Cambridge, MA: The Belknap Press of Harvard University Press.

Schneider, Daniel. 2011. "Wealth and the Marital Divide." American Journal of Sociology 117 (2):627-67. https://doi.org/10.1086/661594.

Smock, Pamela J., Wendy D. Manning, and Meredith Porter. 2005. “"Everything's There Except Money': How Money Shapes Decisions to Marry Among Cohabitors." Journal of Marriage and Family 67 (3):680-96. https://doi.org/10.1111/j.1741-3737.2005.00162.x.

Solon, Gary. 1992. "Intergenerational Income Mobility in the United States." The American Economic Review 82 (3):393-408.

Spilerman, Seymour. 2000. "Wealth and Stratification Processes." Annual Review of Sociology 26:497-524.

Spilerman, Seymour, and Francois-Charles Wolff. 2012. "Parental Wealth and Resource Transfers: How They Matter in France for Home Ownership and Living Standards." Social Science Research 41 (2):207-23. https://doi.org/10.1016/j.ssresearch.2011.08.002.

Swartz, Teresa Toguchi. 2009. "Intergenerational Family Relations in Adulthood: Patterns, Variations, and Implications in the Contemporary United States." Annual Review of Sociology 35:191-212. https://doi.org/10.1146/annurev.soc.34.040507.134615.

Torche, Florencia. 2015. "Analyses of Intergenerational Mobility: An Interdisciplinary Review." The ANNALS of the American Academy of Political and Social Science 657 (1):37-62. https://doi.org/10.1177/0002716214547476.

United States Census Bureau. 2017. "Table C4. Children With Grandparents By Presence Of Parents, Sex, And Selected Characteristics: 2016.” America's Families and Living 
Arrangements: 2016. April 6, 2017.

https://www.census.gov/data/tables/2016/demo/families/cps-2016.html.

Warren, John Robert, and Robert M. Hauser. 1997. "Social Stratification across Three Generations: New Evidence from the Wisconsin Longitudinal Study." American Sociological Review 62 (4):561-72. https://doi.org/10.2307/2657426.

Wightman, Patrick, and Sheldon Danziger. 2014. "Multi-Generational Income Disadvantage and the Educational Attainment of Young Adults." Research in Social Stratification and Mobility 35:53-69. https://doi.org/10.1016/j.rssm.2013.09.004.

Wolff, Edward N. 2016. "Household Wealth Trends in the United States, 1962 to 2013: What Happened over the Great Recession?" Russell Sage Foundation Journal of the Social Sciences 2 (6):24-43.

Zagorsky, Jay L. 2005. "Marriage and Divorce's Impact on Wealth.” Journal of Sociology 41 (4):406-24. https://doi.org/10.1177/1440783305058478. 


\section{TABLes \& Figures}

\section{Table 1. Descriptives}

\begin{tabular}{|c|c|c|c|c|}
\hline & \multicolumn{2}{|c|}{$\begin{array}{c}\text { 2-gen. sample } \\
(\mathrm{N}=4,608)\end{array}$} & \multicolumn{2}{|c|}{$\begin{array}{c}\text { 3-gen. sample } \\
(\mathrm{N}=2,532)\end{array}$} \\
\hline & Mean or $\%$ & (Std.Dev.) & Mean or $\%$ & (Std.Dev.) \\
\hline \multicolumn{5}{|l|}{ Demographics } \\
\hline \multicolumn{5}{|l|}{ Age } \\
\hline G3/offspring: Age in 2013 & 44.5 & (10.7) & 37.0 & (8.5) \\
\hline G2/parents: Average age in 1984 & 43.4 & $(10.9)$ & 35.2 & $(8.1)$ \\
\hline G1/grandparents: Average age in 1968 (housing wealth sample) & & & 46.7 & (9.6) \\
\hline G1/grandparents: Average age in 1984 (net worth sample) & & & 61.6 & $(8.8)$ \\
\hline \multicolumn{5}{|l|}{ Offspring Age Groups (age in 2013) } \\
\hline Age group 25-34 & $22.4 \%$ & & $45.1 \%$ & \\
\hline Age group 35-44 & $27.2 \%$ & & $37.2 \%$ & \\
\hline Age group $45-54$ & $29.2 \%$ & & $12.9 \%$ & \\
\hline Age group 55-64 & $21.1 \%$ & & $4.8 \%$ & \\
\hline \multicolumn{5}{|l|}{ Offspring Race } \\
\hline White & $83.3 \%$ & & $79.6 \%$ & \\
\hline African-American & $12.3 \%$ & & $15.4 \%$ & \\
\hline Other & $4.4 \%$ & & $5.0 \%$ & \\
\hline \multicolumn{5}{|l|}{ Offspring Sex } \\
\hline Male & $47.8 \%$ & & $46.9 \%$ & \\
\hline Female & $52.2 \%$ & & $53.1 \%$ & \\
\hline \multicolumn{5}{|l|}{ Net worth } \\
\hline \multicolumn{5}{|l|}{ Net worth } \\
\hline G3/Offspring: Average 2013-2015 & 330,022 & $1,093,762$ & 153,834 & 645,893 \\
\hline G3/Offspring: Average 2005-2007 (pre-recession) & 327,137 & $1,234,414$ & 127,897 & 386,039 \\
\hline G2/Parent: Average 1984-1989 & 352,727 & $1,012,219$ & 188,322 & 450,474 \\
\hline G1/Grandparent: Average 1984-1989 & & & 396,353 & $1,018,362$ \\
\hline \multicolumn{5}{|l|}{ Share of cases without wealth (zero or net debt) } \\
\hline G3/Offspring: 2013-2015 & $16.8 \%$ & & $23.1 \%$ & \\
\hline G3/Offspring: 2005-2007 (pre-recession) & $14.0 \%$ & & $20.5 \%$ & \\
\hline G2/Parent: 1984-1989 & $5.5 \%$ & & $8.1 \%$ & \\
\hline G1/Grandparent: 1984-1989 (self-reported) & & & $3.4 \%$ & \\
\hline
\end{tabular}




\begin{tabular}{|c|c|c|c|c|}
\hline & \multicolumn{2}{|c|}{$\begin{array}{c}\text { 2-gen. sample } \\
(\mathrm{N}=4,608)\end{array}$} & \multicolumn{2}{|c|}{$\begin{array}{c}\text { 3-gen. sample } \\
(\mathrm{N}=2,532)\end{array}$} \\
\hline & Mean or $\%$ & (Std.Dev.) & Mean or $\%$ & (Std.Dev.) \\
\hline \multicolumn{5}{|c|}{ Net worth quintiles G3/offspring (average 2013-2015) } \\
\hline Quintile 1 (lowest) & $-31,650$ & & & \\
\hline Quintile 2 & 16,385 & & & \\
\hline Quintile 3 & 73,986 & & & \\
\hline Quintile 4 & 230,250 & & & \\
\hline Quintile 5 (highest) & $1,362,410$ & & & \\
\hline \multicolumn{5}{|c|}{ Net worth quintiles: G2/parents (average 1984-1989) } \\
\hline Quintile 1 (lowest) & 4,102 & & & \\
\hline Quintile 2 & 56,805 & & & \\
\hline Quintile 3 & 140,027 & & & \\
\hline Quintile 4 & 291,958 & & & \\
\hline Quintile 5 (highest) & $1,271,796$ & & & \\
\hline \multicolumn{5}{|l|}{ Housing Wealth } \\
\hline \multicolumn{5}{|l|}{ Home value } \\
\hline G3/Offspring: Average 2013-2015 & 175,493 & $(232,799)$ & 124,709 & $(177,486)$ \\
\hline G2/Parent: Average 1984-1989 & 147,149 & $(154,569)$ & 126,369 & $(145,984)$ \\
\hline G1/Grandparent: Average 1968-1969 & & & 95,616 & $(87,780)$ \\
\hline \multicolumn{5}{|l|}{ Share of Homeowners } \\
\hline G3/Child: 2013-2015 & $69.0 \%$ & & $57.9 \%$ & \\
\hline G2/Parent: 1984-1989 & $82.5 \%$ & & $76.8 \%$ & \\
\hline G1/Grandparent: 1968-1969 & & & $76.0 \%$ & \\
\hline \multicolumn{5}{|l|}{ Education } \\
\hline \multicolumn{5}{|l|}{ G3/Offspring: Highest degree attained (2013) } \\
\hline Less than high school & $4.6 \%$ & & $4.4 \%$ & \\
\hline High school & $24.9 \%$ & & $22.7 \%$ & \\
\hline Some college & $32.9 \%$ & & $36.7 \%$ & \\
\hline BA & $23.6 \%$ & & $25.1 \%$ & \\
\hline Post-graduate & $14.0 \%$ & & $11.1 \%$ & \\
\hline \multicolumn{5}{|l|}{ G2/Parent: Highest degree attained (1984) } \\
\hline Less than high school & & & $16.0 \%$ & \\
\hline High school & & & $42.7 \%$ & \\
\hline Some college & & & $22.1 \%$ & \\
\hline BA & & & $15.0 \%$ & \\
\hline Post-graduate & & & $4.2 \%$ & \\
\hline
\end{tabular}


2-gen. sample $(\mathrm{N}=4,608)$

Mean or \% (Std.Dev.) 3-gen. sample

$(\mathrm{N}=2,532)$

\section{Inheritance}

Offspring: Large inheritance or gift received (through 2013)

Whether ever received

$28.8 \%$

$19.2 \%$

Value of gift/inheritance

52,100

$(494,535)$

33,584

$(569,931)$

Parent: Large inheritance or gift received (through 1984)

Whether ever received

$11.3 \%$

Value of gift/inheritance

5,309

\section{Marriage}

Offspring: Whether married (2013)

Parent: Whether married (1984)

\section{Business Ownership}

Offspring: Whether business owner (2013)

$10.8 \%$

$8.2 \%$

Parent: Whether business owner (1984)

$14.0 \%$

Home Ownership

Offspring: Years of home ownership as fraction of observed (2013)

$52.8 \%$

$43.2 \%$

Parents: Years of home ownership as fraction of observed (1984)

Notes:

(a) All dollar values are 2015-\$

(b) Statistics for the 3-generational sample refer to the sample defined based on grandparental housing wealth in 1968/1969 (with the exception of self-reported grandparental net worth in 1984/1989, which is based on the corresponding three-generational sample with $\mathrm{N}=2,180$ ) 
Table 2. Intergenerational Correlations in Net Worth

\begin{tabular}{llll}
\hline & & & \\
& Rank Slope & (SE) & N \\
\hline & & & \\
Overall & $0.390^{* * *}$ & $(0.020)$ & 4,608 \\
By Age (4 groups) & & & \\
(1) Age 25-34 & & & \\
(2) Age 35-44 & $0.329 * * *$ & $(0.039)$ & 1,329 \\
(3) Age 45-54 & $0.374^{* * *}$ & $(0.039)$ & 1,278 \\
(4) Age 55-64 & $0.390^{* * *}$ & $(0.034)$ & 1,193 \\
& $0.443^{* * *}$ & $(0.040)$ & 808 \\
By Age (2 groups) & & & \\
(5) Age 25-44 & & & \\
(6) Age 45-64 & $0.362^{* * *}$ & $(0.027)$ & 2,607 \\
& $0.412^{* * *}$ & $(0.027)$ & 2,001 \\
\hline & & & \\
Test of Differences (p-values) & & & \\
(2) vs. (1) & & & \\
(3) vs. (1) & 0.363 & & \\
(4) vs. (1) & 0.204 & & \\
(6) vs. (5) & 0.042 & & \\
\end{tabular}

Note: Statistical significance levels at $+\mathrm{p}<.10,{ }^{*} \mathrm{p}<.05, * * \mathrm{p}<.01$, and $* * * \mathrm{p}<.001$ based on two-tailed tests. 
Table 3. Multigenerational Correlations in Net Worth and Home Values

Rank slopes, with controls for age and squared age in each generation

\begin{tabular}{|c|c|c|c|c|}
\hline \multirow[b]{3}{*}{ A: Net Worth } & \multirow{2}{*}{$\begin{array}{l}\text { Two-Gen. Sample } \\
\text { (1) }\end{array}$} & \multicolumn{3}{|c|}{ Three-Generational Sample } \\
\hline & & (2) & (3) & (4) \\
\hline & & & & \\
\hline \multirow[t]{2}{*}{ Parental } & $0.390 * * *$ & $0.320 * * *$ & & $0.247 * * *$ \\
\hline & $(0.020)$ & $(0.032)$ & & $(0.036)$ \\
\hline \multirow[t]{2}{*}{ Grandparental (in 1984/1989) } & & & $0.230 * * *$ & $0.121 * * *$ \\
\hline & & & $(0.027)$ & $(0.028)$ \\
\hline $\mathrm{R}^{2}$ & & 0.147 & 0.121 & 0.164 \\
\hline $\mathrm{N}$ & 4,608 & 2,180 & 2,180 & 2,180 \\
\hline \multicolumn{5}{|l|}{ B: Home Value } \\
\hline \multirow[t]{2}{*}{ Parental } & $0.371 * * *$ & $0.348 * * *$ & & $0.304 * * *$ \\
\hline & $(0.024)$ & $(0.034)$ & & $(0.037)$ \\
\hline \multirow[t]{2}{*}{ Grandparental (in 1968/69) } & & & $0.209 * * *$ & $0.107 * * *$ \\
\hline & & & $(0.031)$ & $(0.031)$ \\
\hline $\mathrm{R}^{2}$ & & 0.146 & 0.097 & 0.160 \\
\hline $\mathrm{N}$ & 4,608 & 2,532 & 2,532 & 2,532 \\
\hline
\end{tabular}

Note: Statistical significance levels at $* \mathrm{p}<.05, * * \mathrm{p}<.01$, and $* * * \mathrm{p}<.001$ based on two-tailed tests. 
Table 4. Channels of Inter- and Multigenerational Wealth Transmission

Age 45-64

\begin{tabular}{|c|c|c|c|}
\hline & $\begin{array}{r}\text { 2-gen } \\
\text { Net Worth } \\
(\mathrm{N}=2,001)\end{array}$ & $\begin{array}{r}2 \text {-gen } \\
\text { Home Value } \\
(\mathrm{N}=1,992)\end{array}$ & $\begin{array}{r}\text { 3-gen } \\
\text { Home Value } \\
(\mathrm{N}=359)\end{array}$ \\
\hline Large inheritance or gift received: cumulative value (IHS transformed) & $12.3 \%$ & $12.6 \%$ & $-0.2 \%$ \\
\hline Education: highest degree attained & $25.5 \%$ & $27.2 \%$ & $55.0 \%$ \\
\hline Marriage: currently married (yes/no) & $14.2 \%$ & $17.7 \%$ & $5.2 \%$ \\
\hline Business Ownership: currently homeowner (yes/no) & $8.0 \%$ & $3.9 \%$ & $27.3 \%$ \\
\hline Home Ownership: years of home ownership (fraction of observed years) & $28.4 \%$ & & \\
\hline \multicolumn{4}{|l|}{ Joint Consideration } \\
\hline All mediators & $60.2 \%$ & & \\
\hline All mediators, except inheritance/gift & $55.6 \%$ & & \\
\hline All mediators, except home ownership & & $45.4 \%$ & $4.1 \%$ \\
\hline All mediators, except home ownership \& inheritance/gift & & $41.5 \%$ & $9.4 \%$ \\
\hline
\end{tabular}

Notes:

2-gen: Mediation of parent-child correlation in net worth / home value (rank slope) through child characteristics (percent reduction of correlation when controls are introduced)

3-gen: Mediation of conditional grandparent-child correlation in home values (rank slope, cond. on parental home value) through parent \& child characteristics (percent reduction of correlation when controls are introduced) 
Table 5. Group Differences in Wealth Correlations

\begin{tabular}{|c|c|c|c|c|c|c|}
\hline & $\begin{array}{r}\text { 2-gen } \\
\text { Rank Slope } \\
\text { Net Worth }\end{array}$ & (SE) & $\mathbf{N}$ & $\begin{array}{r}\text { 3-gen } \\
\text { Rank Slope } \\
\text { Home Value }\end{array}$ & (SE) & $\mathbf{N}$ \\
\hline \multicolumn{7}{|l|}{ By Sex } \\
\hline (1) Male & $0.400 * * *$ & $(0.028)$ & 2,051 & $0.101 *$ & $(0.043)$ & 1,122 \\
\hline (2) Female & $0.381 * * *$ & $(0.026)$ & 2,557 & $0.110 * *$ & $(0.038)$ & 1,410 \\
\hline \multicolumn{7}{|l|}{ By Race } \\
\hline (3) White & $0.364 * * *$ & $(0.023)$ & 2,771 & $0.072 *$ & $(0.034)$ & 1,470 \\
\hline (4) African-American & $0.179 * *$ & $(0.058)$ & 1,665 & 0.067 & $(0.091)$ & 957 \\
\hline \multicolumn{7}{|l|}{ By Period } \\
\hline (5) Pre-Recession (2005-2007) & $0.348 * * *$ & $(0.020)$ & 4,001 & $0.105 * *$ & $(0.034)$ & 1,999 \\
\hline (6) Post-Recession (2013-2015) & $0.390 * * *$ & $(0.020)$ & 4,608 & $0.107 * * *$ & $(0.031)$ & 2,532 \\
\hline \multicolumn{7}{|l|}{ By Race \& Period } \\
\hline (7) White, Pre-Recession & $0.324 * * *$ & $(0.024)$ & 2,453 & 0.054 & $(0.036)$ & 1,176 \\
\hline (8) White, Post-Recession & $0.364 * * *$ & $(0.023)$ & 2,771 & $0.072 *$ & $(0.034)$ & 1,470 \\
\hline (9) African-Americans, Pre-Recession & $0.128 *$ & $(0.054)$ & 1,407 & 0.151 & $(0.173)$ & 744 \\
\hline (10) African-Americans, Post-Recession & $0.179 * *$ & $(0.058)$ & 1,665 & 0.067 & $(0.091)$ & 957 \\
\hline \multicolumn{7}{|l|}{ Test of Differences (p-values) } \\
\hline (1) vs. (2) & 0.613 & & & 0.868 & & \\
\hline (3) vs. (4) & 0.000 & & & 0.929 & & \\
\hline (5) vs. (6) & 0.003 & & & 0.945 & & \\
\hline (7) vs. (8) & 0.017 & & & 0.574 & & \\
\hline (9) vs. (10) & 0.805 & & & 0.495 & & \\
\hline
\end{tabular}

Note: Statistical significance levels at $* \mathrm{p}<.05, * * \mathrm{p}<.01$, and $* * * \mathrm{p}<.001$ based on two-tailed tests. Three-generational estimates are conditional on parental home values. 
Figure 1. Race Differences in Intergenerational Wealth Correlations

Binned scatterplot (with bins defined as wealth deciles) and linear fit; age 45-64.

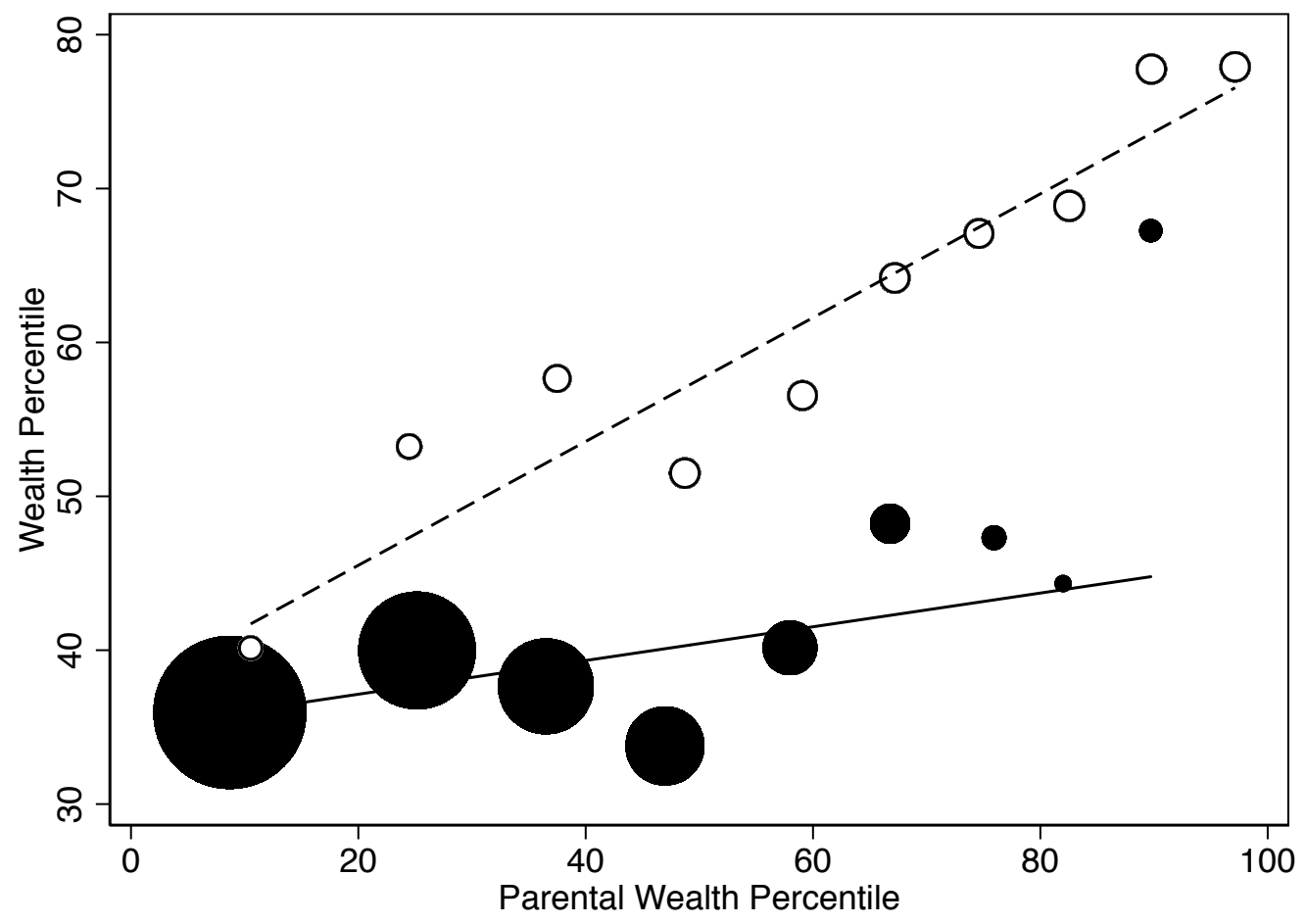

Notes:

(a) Hollow circles $\&$ dashed line $=$ Whites $(\mathrm{N}=1,135)$.

(b) Solid circles $\&$ solid line $=$ African-Americans $(\mathrm{N}=802)$ 


\section{ONLINE SUPPLEMENT}

\section{Appendix A. Mediation of Wealth Correlations: Comparison to Charles and Hurst}

Charles and Hurst (2003) also consider mechanisms of intergenerational wealth transmission, specifically (lifetime) income, education, prior transfers and anticipated bequests, and the types

of assets held. To assess the role of each channel, they add controls for both the parent and child value to the regression model estimating the two-generational association in wealth. They find that estimated lifetime family income is the largest contributor to the intergenerational wealth association, explaining 52 percent of the association. Education explains 28 percent of the association, 17 percent is explained by prior gifts received by the child and anticipated bequests of the parents, and 36 percent is explained by portfolio composition. Net of similarities in income, education and transfers have little additional explanatory power. However, portfolio composition explains an additional 11 percent of the intergenerational association, net of income.

We pursue a different approach. First, in our analysis of the mediation of two-generational correlations, we adjust for children's characteristics (receipt of gifts and bequests, educational attainment, marriage, homeownership, and business ownership), but not the characteristics of parents. Similarly, in our analysis of the mediation of three-generational correlations we do not adjust for characteristics of grandparents, but we adjust for the characteristics of both parents and children. Charles and Hurst aim to estimate to what extent intergenerational wealth reproduction is explained by other characteristics of both parents and children. In contrast, we consider as channels of transmission the mediating pathway from parental to offspring wealth, ignoring the direct intergenerational transmission of other, associated characteristics (like parental education) and the direct effects of these parental traits on offspring wealth. Our approach is in keeping with our descriptive focus on channels of wealth transmission: we seek to understand the potential role for parental wealth in facilitating offspring wealth through investments in other child 
outcomes. Because the mediating channels are positively correlated between parents and children, our estimates will be more conservative in terms of the share of the wealth correlation explained by each factor, while Charles and Hurst's residual wealth association net of controls in both generations will be a more conservative estimate of the causal effect of parental wealth on offspring wealth.

Second, we do not treat income as an independent mediating channel. Charles and Hurst's finding that education explains little of the intergenerational transmission of wealth net of income is important, as it indicates that the importance of education as a channel of transmission is largely through education's effect on income, rather than other mechanisms, such as enhanced financial skills. However, interpreting the mediating role of income is challenging: we learn that much of the between-generation similarity in wealth is because of income in the parent and child generations, but we still do not know why this is true. By focusing on education, marriage, homeownership, business ownership, and gifts and inheritances, we identify channels that are more directly subject to (grand)parental manipulation - (grand)parental action that seeks to increase offspring wealth directly through transfers or indirectly through investments in their future income- and wealth-generating potential. 


\section{APPENDiX B. ACCOUnTING FOR Wealth in Both GrandParental Lineages}

The prospective panel design of the PSID implies that we typically only observe either maternal or paternal grandparents. Not knowing the wealth of one set of grandparents may lead to conservative estimates of multigenerational associations. To directly address this potential bias, we use data from the 1988 PSID "transfer module" that asked respondents to report the wealth of their parents and parents-in-law, thereby capturing the net worth of both paternal and maternal grandparents in our sample $(\mathrm{N}=570)$.

Mean grandparental net worth (G1) as reported by parents (G2) in 1988 is somewhat lower than grandparents' self-reports in 1984/1989 (\$320,989 versus self-reported \$396,353), despite the fact that parents are reporting on both lineages (their own parents and their parents-in-law), while grandparents report only on their own wealth. A somewhat greater share of parents report grandparental zero wealth or net debt (4.8 percent) than self-reported by grandparents (3.4 percent). These disparities suggest that parents' reports of grandparental wealth in 1988 may suffer from substantial measurement error, which would risk downward-biasing our estimates of the multigenerational wealth association. For this reason, we do not use the 1988 wealth reports for our estimates of the multigenerational association in net worth. Instead, we use the 1988 sample only to estimate how the multigenerational wealth associations change when the net worth of one rather than both grandparental lineages are used.

Nevertheless, this multigenerational sample provides a very similar estimate of the threegenerational association in net worth (0.212 compared to 0.230 and 0.209 based on our main multigenerational samples). The estimated two-generational association in this sample is higher (column 2) than in our main multigenerational samples (0.464 compared to 0.320 and 0.348$)$. However, as stated above, the main use of this additional multigenerational sample is to assess 
whether the restriction to a single grandparental lineage is likely to have significantly biased the estimated multigenerational associations reported above.

To accomplish this, we compare the multigenerational associations in grandparental wealth summed across maternal and paternal grandparents (Table B.1, section 1) to associations based on only maternal (section 2) or paternal (section 3) grandparents within the same sample.

Maternal grandparental wealth alone nearly perfectly replicates the unconditional multigenerational association based on total grandparental wealth $(0.207$ versus 0.212 based on total wealth), while the association based on the paternal lineage is somewhat weaker $(0.179){ }^{12}$ By contrast, the conditional multigenerational association is somewhat higher for the paternal lineage alone $(0.073)$ than for total grandparental wealth $(0.065)$, which is in turn somewhat higher than for the maternal lineage alone (0.058). This comparison gives additional credibility to the main estimates of multigenerational associations: our estimates based only on one grandparental lineage are unlikely to substantially understate the grandparent-grandchild association in wealth.

\footnotetext{
${ }^{12}$ The difference between estimates based on the maternal versus paternal lineage is not statistically significant. Similarly, in our main multigenerational analyses we do not find different associations based on whether the maternal or paternal lineage provides the grandparental wealth measure.
} 
Table B.1: Multigenerational Correlations Based on Both Grandparental Lineages

Rank slopes, with controls for age and squared age in each generation

\begin{tabular}{|c|c|c|c|c|}
\hline & \multirow{2}{*}{$\begin{array}{l}\text { Two-Gen. Sample } \\
(1)\end{array}$} & \multicolumn{3}{|c|}{ Three-Generational Sample } \\
\hline & & (2) & (3) & (4) \\
\hline \multicolumn{5}{|c|}{ (1) Net Worth (both lineages observed) } \\
\hline \multirow[t]{2}{*}{ Parental } & $0.390 * * *$ & $0.464 * * *$ & & $0.415 * * *$ \\
\hline & $(0.020)$ & $(0.053)$ & & $(0.054)$ \\
\hline \multirow[t]{2}{*}{ Grandparental (1988 proxy report) } & & & $0.212 * * *$ & 0.065 \\
\hline & & & $(0.050)$ & $(0.049)$ \\
\hline $\mathrm{R}^{2}$ & 0.275 & 0.205 & 0.118 & 0.218 \\
\hline $\mathrm{N}$ & 4,608 & 570 & 570 & 570 \\
\hline \multicolumn{5}{|c|}{ (2) Net Worth (maternal lineage only; where both observed) } \\
\hline \multirow{2}{*}{ Parental } & $0.390 * * *$ & $0.464 * * *$ & & $0.416^{* * *}$ \\
\hline & $(0.020)$ & $(0.053)$ & & $(0.052)$ \\
\hline \multirow[t]{2}{*}{ Grandmaternal (1988 proxy report) } & & & $0.207 * * *$ & 0.058 \\
\hline & & & $(0.050)$ & $(0.047)$ \\
\hline $\mathrm{R}^{2}$ & 0.275 & 0.205 & 0.118 & 0.218 \\
\hline $\mathrm{N}$ & 4,608 & 570 & 570 & 570 \\
\hline \multicolumn{5}{|c|}{ (3) Net Worth (paternal lineage only; where both observed) } \\
\hline \multirow[t]{2}{*}{ Parental } & $0.390 * * *$ & $0.464 * * *$ & & $0.421 * * *$ \\
\hline & $(0.020)$ & $(0.053)$ & & $(0.057)$ \\
\hline \multirow[t]{2}{*}{ Grandpaternal (1988 proxy report) } & & & $0.179 * * *$ & 0.073 \\
\hline & & & $(0.049)$ & $(0.047)$ \\
\hline $\mathrm{R}^{2}$ & 0.275 & 0.205 & 0.105 & 0.22 \\
\hline $\mathrm{N}$ & 4,608 & 570 & 570 & 570 \\
\hline
\end{tabular}

Note: Statistical significance levels at $* \mathrm{p}<.05, * * \mathrm{p}<.01$, and $* * * \mathrm{p}<.001$ based on two-tailed tests. 


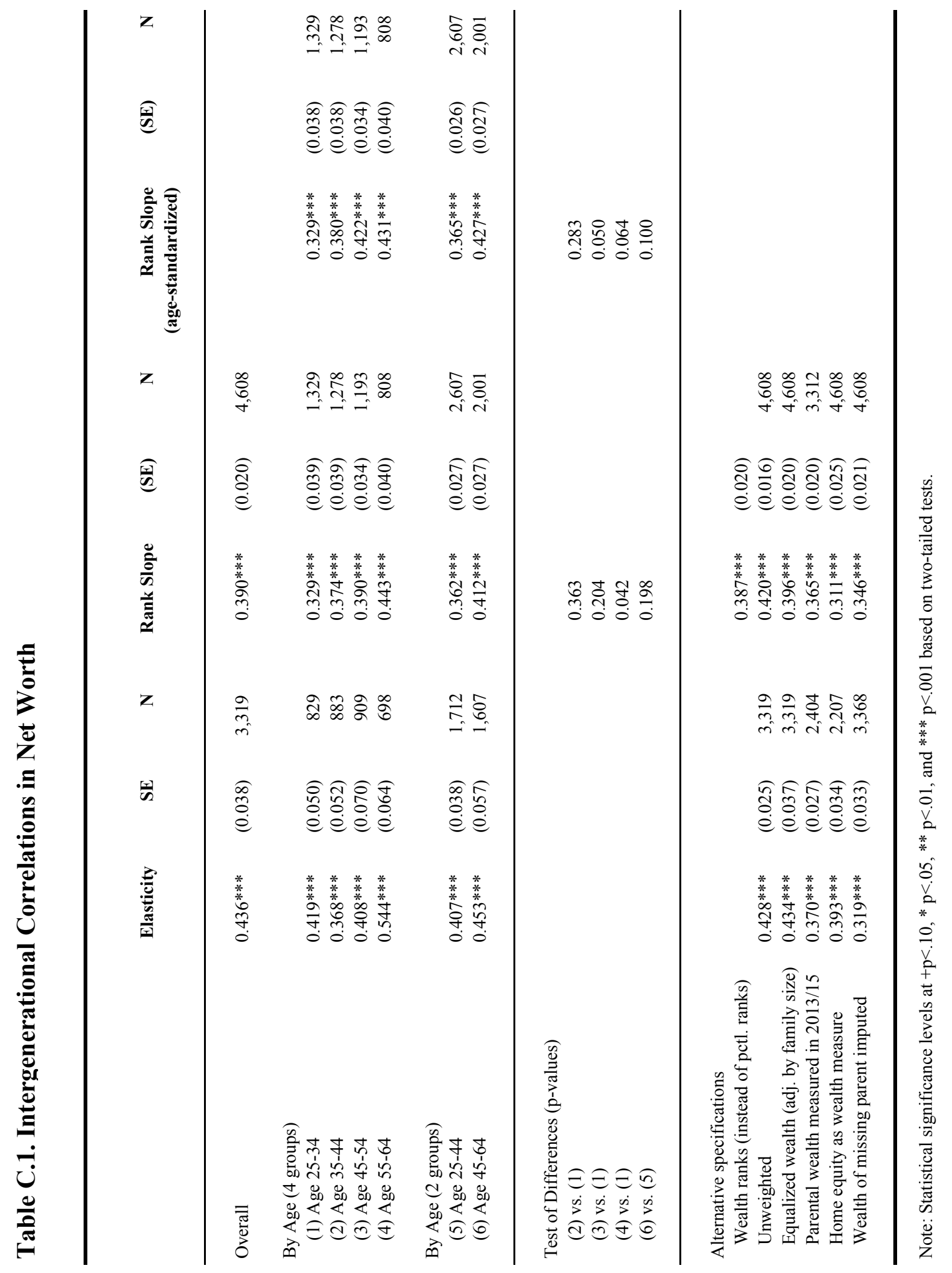




\section{Table C.2. Wealth Mobility}

\begin{tabular}{|c|c|c|c|c|c|c|c|}
\hline \multirow{2}{*}{\multicolumn{2}{|c|}{ Parental Wealth Quintile }} & \multicolumn{6}{|c|}{ Child's Wealth Quintile } \\
\hline & & $\begin{array}{r}\text { Lowest } \\
{[<\$ 15 \mathrm{k}]}\end{array}$ & $\begin{array}{c}\text { Quintile } 2 \\
{[\$ 16 \mathrm{k}-\$ 87 \mathrm{k}]}\end{array}$ & $\begin{array}{c}\text { Quintile } 3 \\
{[\$ 88 \mathrm{k}-\$ 246 \mathrm{k}]}\end{array}$ & $\begin{array}{c}\text { Quintile } 4 \\
{[\$ 247 \mathrm{k}-\$ 627 \mathrm{k}]}\end{array}$ & $\begin{array}{c}\text { Highest } \\
{[>=\$ 631 \mathrm{k}]}\end{array}$ & Total \\
\hline Lowest & {$[<=\$ 58 \mathrm{k}]$} & 39.0 & 29.0 & 17.7 & 7.1 & 7.2 & 100.0 \\
\hline Quintile 2 & {$[\$ 59 \mathrm{k}-\$ 153 \mathrm{k}]$} & 25.3 & 27.0 & 23.3 & 13.4 & 11.1 & 100.0 \\
\hline Quintile 3 & {$[\$ 153 \mathrm{k}-\$ 280 \mathrm{k}]$} & 18.2 & 21.9 & 24.0 & 21.2 & 14.7 & 100.0 \\
\hline Quintile 4 & {$[\$ 283 \mathrm{k}-\$ 545 \mathrm{k}]$} & 11.6 & 14.4 & 21.5 & 27.6 & 24.8 & 100.0 \\
\hline Highest & {$[>=\$ 548 \mathrm{k}]$} & 6.1 & 7.3 & 13.8 & 30.6 & 42.1 & 100.0 \\
\hline Total & & 20.1 & 19.9 & 20.1 & 20.0 & 20.0 & \\
\hline
\end{tabular}

Note: Children aged 45-64 (N=2,001); quintiles drawn within that population and quintile boundaries in 2015-\$. 


\begin{tabular}{|c|c|c|c|}
\hline & $\begin{array}{r}\text { 2-gen } \\
\text { Net Worth } \\
(\mathrm{N}=2,001)\end{array}$ & $\begin{array}{r}2 \text {-gen } \\
\text { Home Value } \\
(\mathrm{N}=1,992)\end{array}$ & $\begin{array}{r}\text { 3-gen } \\
\text { Home Value } \\
(\mathrm{N}=359)\end{array}$ \\
\hline \multicolumn{4}{|l|}{ Gift/Inheritance ( $\geq \$ 10,000$ in each period) } \\
\hline Whether any gift/inheritance received & $10.4 \%$ & $10.9 \%$ & $-2.8 \%$ \\
\hline Value (ihs transformed) & $12.3 \%$ & $12.6 \%$ & $-0.2 \%$ \\
\hline Among those receiving any: value (log transformed) & $13.2 \%$ & $6.2 \%$ & NA \\
\hline \multicolumn{4}{|l|}{ Inheritance: in last calendar year } \\
\hline Whether any gift/inheritance received & $3.8 \%$ & $3.8 \%$ & $-1.4 \%$ \\
\hline Value (ihs transformed) & $4.5 \%$ & $4.2 \%$ & $-2.6 \%$ \\
\hline Among those receiving any: Value (log transformed) & $4.4 \%$ & $1.3 \%$ & NA \\
\hline \multicolumn{4}{|l|}{ Parental/Grandparental Death } \\
\hline At least one grand/parental death observed (by 2013) & $1.8 \%$ & $2.6 \%$ & $0.7 \%$ \\
\hline None, one, or both grand/parents dead by 2013 (counting unobserved gr & $7.1 \%$ & $8.6 \%$ & $4.3 \%$ \\
\hline None, one, or both grand/parents dead by 2013 (among cases with both & $4.7 \%$ & $5.0 \%$ & NA \\
\hline \multicolumn{4}{|l|}{ Education } \\
\hline Years of Education & $23.7 \%$ & $25.7 \%$ & $48.0 \%$ \\
\hline Whether attained BA or more & $19.3 \%$ & $19.0 \%$ & $47.6 \%$ \\
\hline Highest degree received & $25.5 \%$ & $27.2 \%$ & $55.0 \%$ \\
\hline \multicolumn{4}{|l|}{ Marriage } \\
\hline Currently married? & $14.2 \%$ & $17.7 \%$ & $5.2 \%$ \\
\hline Ever married? & $5.3 \%$ & $7.4 \%$ & $21.3 \%$ \\
\hline Total number of years married & $10.9 \%$ & $12.1 \%$ & $12.3 \%$ \\
\hline \multicolumn{4}{|l|}{ Business Ownership } \\
\hline Currently business owner? & $8.0 \%$ & $3.9 \%$ & $27.3 \%$ \\
\hline \multicolumn{4}{|l|}{ Home Ownership } \\
\hline Currently home owner? & $23.6 \%$ & & \\
\hline Ever a home owner? & $10.5 \%$ & & \\
\hline Years in home ownership (as fraction of observed) & $28.4 \%$ & & \\
\hline
\end{tabular}

* Best mediators: Cumulative value of inheritance (ihs), highest educational degree, currently married, value of business (ihs), [for net worth only:] number of years in home ownership $\mathrm{NA}=$ Less than 50 cases 
Table C.4. Wealth Mobility by Race

(1)

\begin{tabular}{|c|c|c|c|c|c|}
\hline \multirow[t]{2}{*}{$\begin{array}{l}\text { Parental } \\
\text { Home Value }\end{array}$} & & \multicolumn{3}{|c|}{ Child's Home Value } & \multirow[b]{2}{*}{ Total } \\
\hline & & None & Lower Half & Upper Half & \\
\hline & \multicolumn{5}{|c|}{ WHITES $(N=2,768)$} \\
\hline None & 13.1 & 47.1 & 33.4 & 19.5 & 100.0 \\
\hline Lower Half & 40.8 & 27.1 & 45.8 & 27.1 & 100.0 \\
\hline Upper Half & 46.2 & 20.5 & 25.4 & 54.1 & 100.0 \\
\hline \multirow[t]{2}{*}{ Total } & 100.0 & 26.6 & 34.8 & 38.6 & 100.0 \\
\hline & \multicolumn{5}{|c|}{ AFRICAN-AMERICANS $(N=1,653)$} \\
\hline None & 45.4 & 70.3 & 27.0 & 2.6 & 100.0 \\
\hline Lower Half & 45.9 & 43.1 & 45.1 & 11.9 & 100.0 \\
\hline Upper Half & 8.7 & 57.8 & 16.7 & 25.5 & 100.0 \\
\hline Total & 100.0 & 56.7 & 34.4 & 8.9 & 100.0 \\
\hline
\end{tabular}

Notes: Children aged 25-64

(2)

Grandparental

Home Value

Child's Home Value

None Lower Half Upper Half Total

$$
\text { WHITES }(N=1,473)
$$

\begin{tabular}{lccccc} 
None & 18.3 & 44.0 & 30.6 & 25.4 & 100.0 \\
Lower Half & 37.1 & 38.1 & 38.3 & 23.5 & 100.0 \\
Upper Half & 44.6 & 34.8 & 29.7 & 35.5 & 100.0 \\
Total & 100.0 & 37.7 & 33.0 & 29.2 & 100.0 \\
& \multicolumn{5}{c}{ AFRICAN-AMERICANS $(N=958)$} \\
& \multicolumn{5}{c}{} \\
None & 50.6 & 67.1 & 27.6 & 5.3 & 100.0 \\
Lower Half & 45.7 & 60.2 & 29.2 & 10.6 & 100.0 \\
Upper Half & 3.6 & 50.0 & 7.7 & 42.3 & 100.0 \\
Total & 100.0 & 63.6 & 27.6 & 9.1 & 100.0 \\
& & & & & \\
\hline
\end{tabular}

Notes: Children aged 25-64 


\section{Table C.5. Channels of Wealth Transmission by Race}

\begin{tabular}{|c|c|c|c|c|}
\hline & \multicolumn{2}{|c|}{ Net Worth } & \multicolumn{2}{|c|}{ Home Value } \\
\hline & $\begin{array}{r}\text { Whites } \\
(\mathrm{N}=1,135)\end{array}$ & $\begin{array}{r}\text { African-Am. } \\
(\mathrm{N}=802)\end{array}$ & $\begin{array}{r}\text { Whites } \\
(\mathrm{N}=1,134)\end{array}$ & $\begin{array}{r}\text { African-Am. } \\
(\mathrm{N}=795)\end{array}$ \\
\hline Large inheritance or gift received: cumulative value (IHS transformed) & $12.2 \%$ & $2.2 \%$ & $11.4 \%$ & $5.2 \%$ \\
\hline Education: highest degree attained & $25.2 \%$ & $42.9 \%$ & $26.7 \%$ & $33.9 \%$ \\
\hline Marriage: currently married (yes/no) & $8.8 \%$ & $11.1 \%$ & $11.5 \%$ & $1.8 \%$ \\
\hline Business Ownership: currently homeowner (yes/no) & $7.6 \%$ & $3.9 \%$ & $2.9 \%$ & $1.7 \%$ \\
\hline Home Ownership: years of home ownership (fraction of observed years) & $19.9 \%$ & $38.7 \%$ & & \\
\hline \multicolumn{5}{|l|}{ Joint Consideration } \\
\hline All mediators & $52.4 \%$ & $67.5 \%$ & & \\
\hline All mediators, except inheritance & $46.9 \%$ & $69.3 \%$ & & \\
\hline All mediators, except home ownership & & & $39.3 \%$ & $32.1 \%$ \\
\hline All mediators, except home ownership \& inheritance & & & $35.6 \%$ & $30.2 \%$ \\
\hline
\end{tabular}

Notes: Children aged 45-64; degree of mediation of 2-generational rank slopes 